\title{
Performance of Solar Electric Powered Deep Space Missions Using Hall Thruster Propulsion
}

Kevin E. Witzberger and David Manzella

Glenn Research Center, Cleveland, Ohio 
Since its founding, NASA has been dedicated to the advancement of aeronautics and space science. The NASA Scientific and Technical Information (STI) Program Office plays a key part in helping NASA maintain this important role.

The NASA STI Program Office is operated by Langley Research Center, the Lead Center for NASA's scientific and technical information. The NASA STI Program Office provides access to the NASA STI Database, the largest collection of aeronautical and space science STI in the world. The Program Office is also NASA's institutional mechanism for disseminating the results of its research and development activities. These results are published by NASA in the NASA STI Report Series, which includes the following report types:

- $\quad$ TECHNICAL PUBLICATION. Reports of completed research or a major significant phase of research that present the results of NASA programs and include extensive data or theoretical analysis. Includes compilations of significant scientific and technical data and information deemed to be of continuing reference value. NASA's counterpart of peerreviewed formal professional papers but has less stringent limitations on manuscript length and extent of graphic presentations.

- TECHNICAL MEMORANDUM. Scientific and technical findings that are preliminary or of specialized interest, e.g., quick release reports, working papers, and bibliographies that contain minimal annotation. Does not contain extensive analysis.

- CONTRACTOR REPORT. Scientific and technical findings by NASA-sponsored contractors and grantees.
- CONFERENCE PUBLICATION. Collected papers from scientific and technical conferences, symposia, seminars, or other meetings sponsored or cosponsored by NASA.

- SPECIAL PUBLICATION. Scientific, technical, or historical information from NASA programs, projects, and missions, often concerned with subjects having substantial public interest.

- TECHNICAL TRANSLATION. Englishlanguage translations of foreign scientific and technical material pertinent to NASA's mission.

Specialized services that complement the STI Program Office's diverse offerings include creating custom thesauri, building customized databases, organizing and publishing research results ... even providing videos.

For more information about the NASA STI Program Office, see the following:

- Access the NASA STI Program Home Page at http://www.sti.nasa.gov

- E-mail your question via the Internet to help@sti.nasa.gov

- Fax your question to the NASA Access Help Desk at 301-621-0134

- Telephone the NASA Access Help Desk at 301-621-0390

- Write to:

NASA Access Help Desk

NASA Center for AeroSpace Information 7121 Standard Drive

Hanover, MD 21076 
NASA/TM-2006-214044

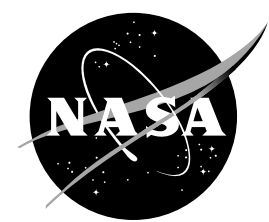

\section{Performance of Solar Electric Powered Deep Space Missions Using Hall Thruster Propulsion}

Kevin E. Witzberger and David Manzella Glenn Research Center, Cleveland, Ohio

Prepared for the 41st Joint Propulsion Conference and Exhibit cosponsored by AIAA, ASME, SAE, and ASEE Tucson, Arizona, July 10-13, 2005

National Aeronautics and

Space Administration

Glenn Research Center 


\section{Acknowledgments}

The research described in this paper was carried out at NASA Glenn Research Center. This work was sponsored

by NASA and managed by Randy Baggett, NASA Marshall Space Flight Center's Project Manager, for Next Generation Electric Propulsion within the In-Space Propulsion Program. Also, thank you to Leon Gefert for his continuous support and feedback.

This report contains preliminary

findings, subject to revision as analysis proceeds.

Trade names or manufacturers' names are used in this report for identification only. This usage does not constitute an official endorsement, either expressed or implied, by the National Aeronautics and Space Administration.

Available from

NASA Center for Aerospace Information 7121 Standard Drive

Hanover, MD 21076
National Technical Information Service 5285 Port Royal Road Springfield, VA 22100 


\title{
Performance of Solar Electric Powered Deep Space Missions Using Hall Thruster Propulsion
}

\author{
Kevin E. Witzberger and David Manzella \\ National Aeronautics and Space Administration \\ Glenn Research Center \\ Cleveland, Ohio 44135
}

Power limited, low-thrust trajectories were assessed for missions to Jupiter, Saturn, and Neptune utilizing a single Venus Gravity Assist (VGA) and a primary propulsion system based on either a 3-kW high voltage Hall thruster, of the type being developed by the NASA In-Space Propulsion Technology Program, or an 8kW variant of this thruster. These Hall thrusters operate with specific impulses below 3,000 seconds. A trade study was conducted to examine mission parameters that include: net delivered mass (NDM), beginning-oflife (BOL) solar array power, heliocentric transfer time, required launch vehicle, number of operating thrusters and throttle profile. The top performing spacecraft configuration was defined to be the one that delivered the highest mass for a range of transfer times. In order to evaluate the potential future benefit of using next generation Hall thrusters as the primary propulsion system, comparisons were made with the advanced state-of-the-art (ASOA), 7-kW, 4,100 second NASA's Evolutionary Xenon Thruster (NEXT) for the same mission scenarios. For the BOL array powers considered in this study $(<30 \mathrm{~kW})$, the results show that the performance of the Hall thrusters, relative to NEXT, is largely dependant on the performance capability of the launch vehicle, and that at least a $10 \%$ performance gain, equating to at least an additional $200 \mathrm{~kg}$ dry mass at each target planet, is achieved over the higher specific impulse NEXT when launched on an Atlas 551.

\section{Nomenclature}

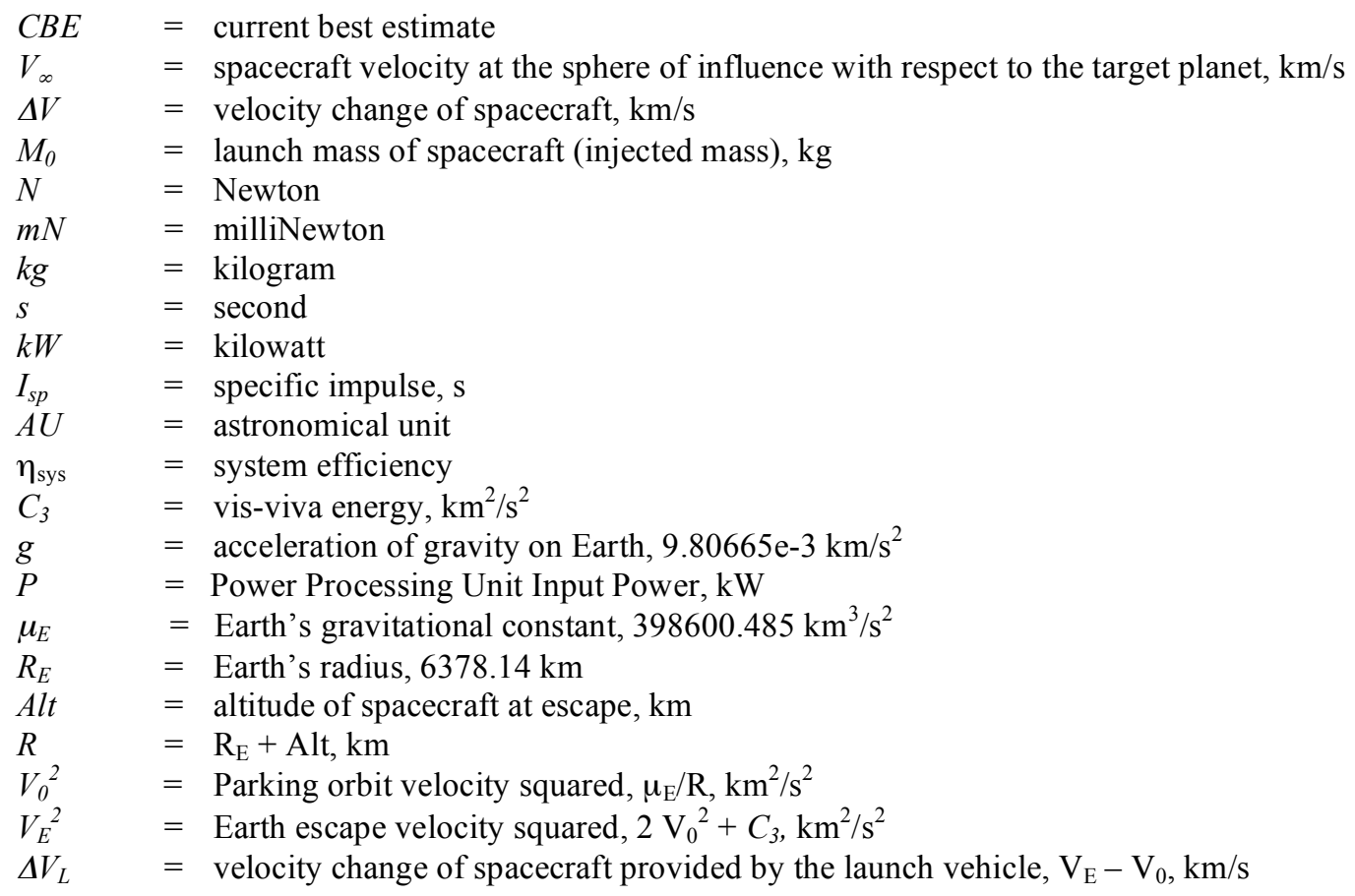




\section{Introduction}

$\mathrm{O}$ bit raising, repositioning, insertion, and de-orbit functions are a few commonly sited applications of Hall thrusters. ${ }^{1,2,3,4}$ When considering Hall thruster technology for interplanetary missions, past works have focused on some sort of Earth escape architecture in which Hall thrusters are used just to spiral out from Earth. ${ }^{2,5}$ This architecture enables a smaller launch vehicle to be used, thereby reducing the overall mission costs. A common theme in past interplanetary mission analysis work is that the optimal specific impulses required for deep space missions are too high for Hall thrusters to attain, implying that the performance of the Hall thrusters would be inferior to the higher $\mathrm{I}_{\mathrm{sp}}$ ion thrusters. ${ }^{6,7,8}$ While this may be true for constant power missions, it does not hold true for certain power-limited deep space missions. Fiehler and Oleson compared Hall and ion technology performance results for direct Earth-Mars Solar Electric Powered (SEP) missions. ${ }^{9}$ Their work showed that a spacecraft with Hall thrusters, using less array power and fewer thrusters, delivered slightly more payload to Mars than a spacecraft with ion thrusters. The low thrust trajectory optimization tool used in their study was based on the Direct Trajectory Optimization Method. This study utilized a calculus-of-variations based optimization code, Solar Electric Propulsion Trajectory Optimization Program (SEPTOP), developed by Carl Sauer at the Jet Propulsion Laboratory (JPL).

The work in this paper goes beyond that of Fiehler and Oleson and assesses the performance of next generation Hall thrusters designed for deep space missions for which the performance of ion thrusters, such as NEXT, have been previously assessed. ${ }^{10,11}$ The main objectives of the mission trade studies were to:

(1) Assess the performance capability of a spacecraft using next generation Hall thrusters for its primary propulsion system by identifying the top performing NEXT and Hall propelled spacecraft to each target planet and comparing the results;

(2) Gain insight into the importance of the combination of the launch vehicle and BOL array power in determining the performance of the next generation Hall thrusters;

(3) Identify thruster performance modifications that would enhance the overall performance on a mission.

These classes of missions are to the outer solar system and typically require a Hohmann-type $\Delta \mathrm{V}$ of $6-8 \mathrm{~km} / \mathrm{s}$. A VGA is used to provide increased heliocentric orbital energy, thereby reducing the launch energy $\left(\mathrm{C}_{3}\right)$ requirement provided by the launch vehicle. Three planets are targeted: Jupiter, Saturn, and Neptune. The NDM at each target planet's sphere of influence (SOI) is the dry mass of all elements of the spacecraft, including the science payload, less the SEP module and propellant. Capturing into a final parking orbit was not a requirement for this study. Parametric analysis is presented in the form of NDM versus trip time for a given BOL array power (referenced at $1 \mathrm{AU}$ ) and launch vehicle for both Hall thrusters and NEXT. The trade-off between the number of operating thrusters and throttling profile are assessed for each destination. The top performing spacecraft configuration for Hall and NEXT is identified and a relative comparison is made.

At this point it is important to point out that although comparisons are made between Hall and NEXT technology, they are at different stages of development. NEXT is the more mature technology; it is an advancement of the current state-of-the-art (SOA) ion thruster, the $2.6-\mathrm{kW}, 3,100$ second NASA Solar Electric Propulsion Technology Application Readiness thruster (NSTAR) that successfully served as the primary propulsion system on Deep Space 1. Notable technological advancements include: increased throttling range (from 5:1 to about 10:1), about a 30\% increase in maximum specific impulse, and nearly a 300\% increase in maximum operating power. A breadboard test has been conducted, and NEXT is on track to be at a NASA technology readiness level (TRL) 6 by the end of 2006. TRL 6 is defined as system/subsystem model or prototype demonstration in a relevant environment. ${ }^{12}$ In-contrast, the $3-\mathrm{kW}$ Hall thruster and its $8-\mathrm{kW}$ variant is currently at TRL 4 , which is defined as analytical and experimental critical function and/or characteristic proof-of-concept. ${ }^{12}$

This paper begins with section II, an overview and status of Hall thruster technology development at Glenn Research Center. A recent overview of NEXT can be found in reference 10. Mission analysis assumptions and results are covered in section III. Finally, overall conclusions about this study are presented in section IV.

\section{Hall Thruster Technology Overview and Status}

Hall thruster technology has been utilized during the past several decades for Earth orbital station-keeping applications at power levels on the order of one kilowatt $(\mathrm{kW})$ per thruster due to its ability to reduce launch mass and increase satellite operational lifetimes. ${ }^{13}$ This success has lead to two Earth orbiting missions utilizing Hall thruster technology for primary propulsion: the United States National Reconnaissance Office's Science Technology 
Experiments spacecraft (STEX) launched in 1998 and the European Space Agency SMART-1 Lunar probe launched in 2003. These spacecraft including their Hall thruster propulsion systems are shown in Fig. 1.

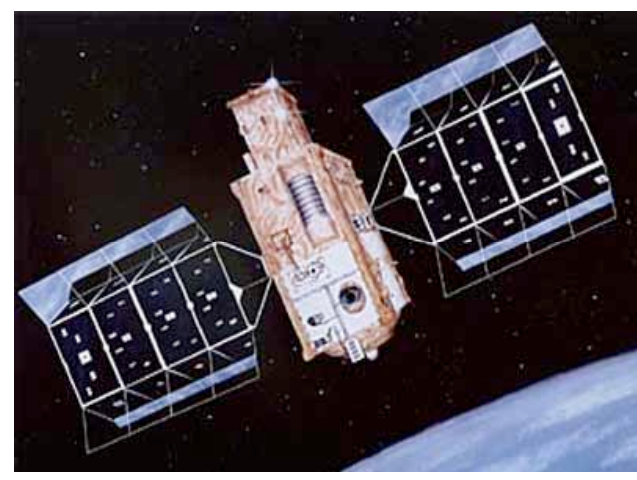

a) STEX

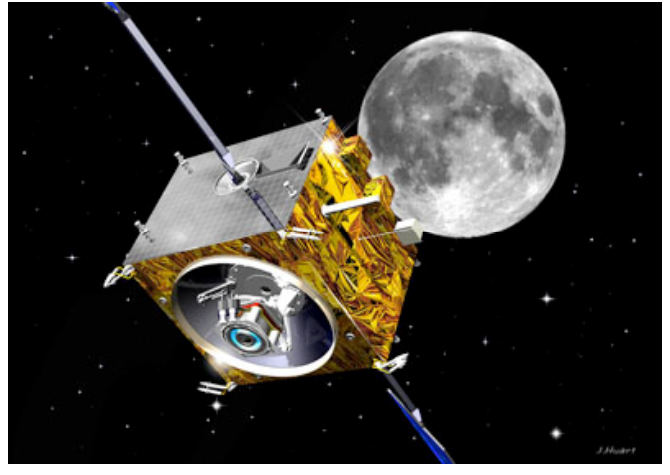

b) SMART-1

\section{Figure 1. Spacecraft that utilize Hall thruster primary propulsion.}

Extending the use of Hall thruster technology to interplanetary missions requires higher powers, increased specific impulse, and for solar electric applications, the ability to operate efficiently over a range of input powers. In response to this, in 1999 NASA initiated a program to develop a Hall thruster that could provide this capability by increasing the specific impulses of existing SOA thrusters from 1500 seconds (sec) to $3000 \mathrm{sec}$ and higher. ${ }^{14}$ The result of this program was the nominally $8-\mathrm{kW}$ NASA-173M thruster, which demonstrated efficient operation at specific impulses from less than $1500 \mathrm{sec}$ to nearly $3400 \mathrm{sec}$ at power levels from less than $1 \mathrm{~kW}$ to nearly $10 \mathrm{~kW} .{ }^{15}$ In 2003 the NASA In-Space Propulsion Program initiated the High Voltage Hall Accelerator (HIVHAC) development project, an effort to further develop this technology to support future robotic space-science exploration missions. While this program initially focused on the 8-kW power level demonstrated by the NASA-173M, in 2004 the power level of interest was reduced to $2.8 \mathrm{~kW}$ (with throttling down to 300 Watts) to optimize the technology for NASA Discovery-Class mission applications. The present study considers the mission benefit of Hall thruster systems utilizing thrusters at both these power levels for representative deep space missions.

While thruster development work is ongoing, the Hall thruster systems used in this analysis were the author's projections based on the current SOA for station-keeping systems and near-term potential capabilities. The technology requirements and remaining technical challenges for each of the components of the Hall thruster system are discussed below.

\section{A. Thruster}

The thrusters used for these analyses were based on the NASA-170M, a flight-like development model of the lab-model NASA-173M thruster, and the NASA-77M, a low power variant being developed by the HIVHAC project. Both these development model thrusters were designed to operate over a wide range of operating voltages and input powers. The performance of the $8-\mathrm{kW}$ thruster was estimated based on experimental data obtained with the laboratory model thruster. The performance of the $2.8-\mathrm{kW}$ thruster was estimated by de-rating the $8-\mathrm{kW}$ performance to account for the greater influence of cathode flow rate and magnet power on the efficiency of the smaller lower power thruster. The In-Space Propulsion Program will verify these estimates through experiments planned for early 2005. Both these thrusters have a TRL of 4 . The thruster mass used in these analyses was estimated from the solid models of the mechanical designs of each thruster. Maximum allowable propellant throughput was estimated at 800 and $300 \mathrm{~kg}$ of xenon based on operational lifetimes of 30,000 hours for the 8-kW and $2.8-\mathrm{kW}$ thrusters respectively. 30,000 hours was selected based on the demonstrated lifetime of the required hollow cathode. ${ }^{16}$ These lifetimes have not been demonstrated and are in excess of the lifetimes required and demonstrated for prior Earth orbital applications. Both thrusters are shown in Fig. 2. 


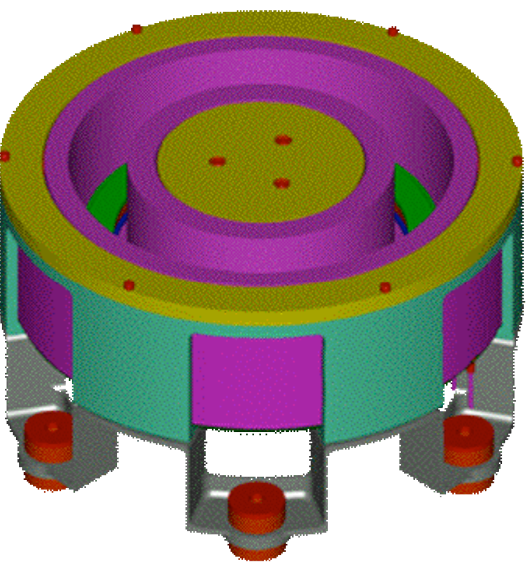

a) 8-kW NASA-170M

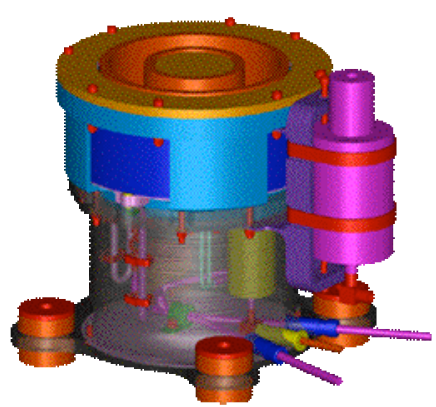

b) 2.8-kW NASA-77M

Figure 2. NASA Hall thrusters.

\section{B. Power Processing Unit}

The power processing units (PPUs) used for these analyses were based on mass and electrical efficiency of the flight units developed for Earth orbital applications. These include the PPU used on the STEX experiment and the PPU undergoing qualification as part of $4.5 \mathrm{~kW}$ Hall Thruster Propulsion System (HTPS) developed for high power geostationary communication satellites. ${ }^{17}$ Each of these units is shown in Fig. 3. All the spacecraft control and telemetry functions are incorporated into the PPU due to its simplicity relative to the PPU of a gridded ion thruster electric propulsion system eliminating the need for a stand alone digital control interface unit (DCIU).

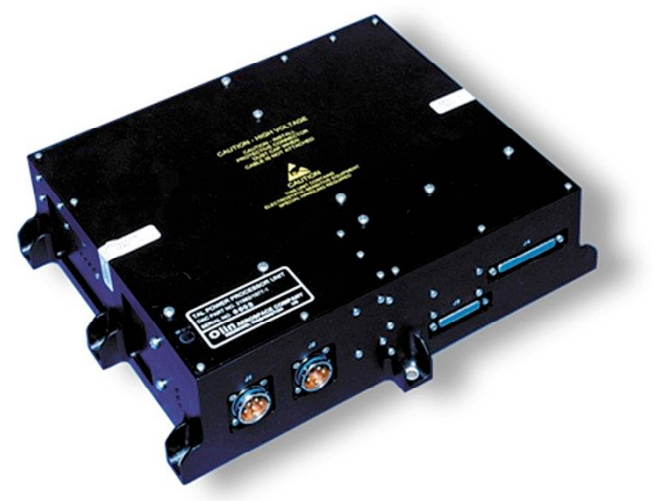

a) 1-kW STEX

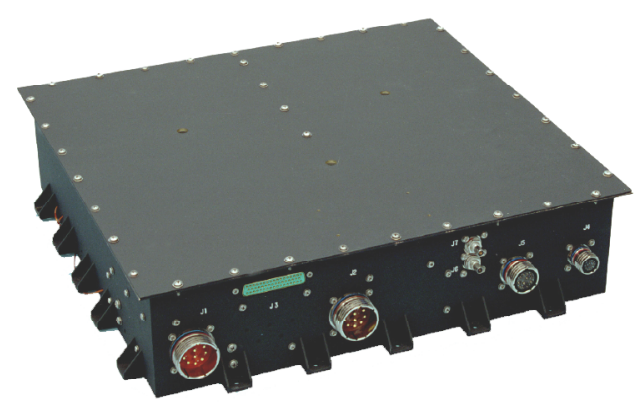

b) $4.5-\mathrm{kW}$ HTPS

Figure 3. Hall Power Processing Units

\section{Propellant Feed System and Xenon Storage}

The feed system and xenon storage tank used for this analysis were based on TRL 6 components previously developed. The feed system uses an industry developed proportional flow control valve from the HTPS system and metal-lined, composite-overwrapped propellant tank as used by the xenon fueled gridded ion thruster system used 
on the NASA Deep Space 1 spacecraft. ${ }^{18}$ The propellant tank was sized as necessary, assuming a constant tankage fraction, depending on the required propellant load.

\section{A. Thruster Modeling}

\section{Mission Analysis}

SEPTOP, an indirect two-body trajectory optimization tool, was used for this analysis. It has the ability to optimize such parameters as launch and fly-by dates and the hyperbolic departure velocity. SEPTOP also optimizes the discrete number of operating thrusters and can insert coast periods. It has been used for many years for many SEP mission analyses across various NASA centers. One important limitation of SEPTOP is that it can only model the thrust or mass flow rate of an individual electric thruster as a function of a single variable: power into the PPU. As a consequence of this limitation, the extreme regions of the thruster performance data are typically modeled, by two polynomial curve fits (one for the thrust and one for the mass flow rate), creating a high thrust and high $\mathrm{I}_{\mathrm{sp}}$ "envelope" around the performance data. In reality, the thruster may be able to physically throttle in a region that is anywhere inside the high thrust and high $\mathrm{I}_{\mathrm{sp}}$ envelope. To better model the thruster, the thrust and mass flow rate would be a function of two variables: PPU input power and a "control" type variable that would be optimized inside the region bounded by high thrust and high $\mathrm{I}_{\mathrm{sp}}$ envelope.

A fourth order polynomial is the maximum order polynomial permitted by SEPTOP. The form of the polynomial is given in Eq. (1), where P is the PPU input power in kilowatts and y represents either thrust or mass flow rate.

$$
y=a+b P+c P^{2}+d P^{3}+e P^{4}
$$

Table 1 provides the operating range of each thruster and the assumed (except for NEXT) PPU efficiencies.

Several versions of the NEXT throttle table exist and have been used for recent mission analyses. ${ }^{10}$ For this analysis a recent NEXT throttle table that provides lower power limits and increased thruster efficiency was used.

Figure 4 shows the curve fits for the $3-\mathrm{kW}$ Hall, 8kW Hall, and 7-kW NEXT. Table 2 provides the corresponding polynomial coefficients.

Table $24^{\text {th }}$ order polynomial curve fit coefficients
Table 1 Minimum and maximum thruster and PPU input powers

\begin{tabular}{|c|c|c|c|c|c|}
\hline \multirow[t]{2}{*}{ Thruster } & \multicolumn{2}{|c|}{$\begin{array}{c}\text { Power into thruster, } \\
\text { kW }\end{array}$} & \multirow{2}{*}{$\begin{array}{c}\text { PPU efficiency, } \\
\% \\
\end{array}$} & \multicolumn{2}{|c|}{ Power into PPU, kW } \\
\hline & Pmin & Pmax & & Pmin & Pmax \\
\hline 3-kW Hall & 0.312 & 2.856 & 95 & 0.328 & 3.006 \\
\hline 8-kW Hall & 1.000 & 8.000 & 96 & 1.042 & 8.333 \\
\hline 7-kW NEXT & 0.743 & 6.864 & $91-95$ & 0.817 & 7.225 \\
\hline
\end{tabular}

\begin{tabular}{|c|c|c|c|c|c|c|c|c|c|c|}
\hline \multirow{3}{*}{ Coefficient } & \multicolumn{2}{|c|}{ 3-kW Hall } & \multicolumn{4}{|c|}{ 8-kW Hall } & \multicolumn{4}{|c|}{ 7-kW NEXT } \\
\hline & \multirow[b]{2}{*}{$\begin{array}{l}\text { Mass flow } \\
\text { rate, } \mathrm{kg} / \mathrm{s}\end{array}$} & \multirow[b]{2}{*}{ Thrust, N } & \multicolumn{2}{|c|}{ High Isp } & \multicolumn{2}{|c|}{ High Thrust } & \multicolumn{2}{|c|}{ High Isp } & \multicolumn{2}{|c|}{ High Thrust } \\
\hline & & & $\begin{array}{l}\text { Mass flow } \\
\text { rate, } \mathrm{kg} / \mathrm{s}\end{array}$ & Thrust, N & $\begin{array}{l}\text { Mass flow } \\
\text { rate, } \mathrm{kg} / \mathrm{s}\end{array}$ & Thrust, N & $\begin{array}{l}\text { Mass flow } \\
\text { rate, } \mathrm{kg} / \mathrm{s}\end{array}$ & Thrust, N & $\begin{array}{l}\text { Mass flow } \\
\text { rate, } \mathrm{kg} / \mathrm{s}\end{array}$ & Thrust, N \\
\hline$a$ & $4.972 \mathrm{E}-07$ & 3.079E-03 & $5.475 \mathrm{E}-08$ & $1.352 \mathrm{E}-03$ & $4.170 \mathrm{E}-07$ & $9.261 \mathrm{E}-03$ & $2.766 \mathrm{E}-06$ & $1.744 \mathrm{E}-02$ & $3.767 \mathrm{E}-06$ & $3.091 \mathrm{E}-02$ \\
\hline b & $2.952 \mathrm{E}-06$ & $5.542 \mathrm{E}-02$ & $1.266 \mathrm{E}-06$ & $3.310 \mathrm{E}-02$ & 1.389E-06 & $2.755 \mathrm{E}-02$ & $-7.854 \mathrm{E}-07$ & $2.948 \mathrm{E}-02$ & $-3.118 \mathrm{E}-06$ & $-3.991 \mathrm{E}-03$ \\
\hline c & $-1.166 \mathrm{E}-06$ & $-1.066 \mathrm{E}-02$ & $4.115 \mathrm{E}-08$ & $1.247 \mathrm{E}-03$ & $4.858 \mathrm{E}-07$ & 1.103E-02 & $2.879 \mathrm{E}-07$ & $-3.420 \mathrm{E}-03$ & $1.856 \mathrm{E}-06$ & 1.990E-02 \\
\hline d & $3.296 \mathrm{E}-07$ & $2.852 \mathrm{E}-03$ & 6.897E-09 & $2.258 \mathrm{E}-04$ & $-7.905 E-08$ & $-1.696 \mathrm{E}-03$ & $-1.514 \mathrm{E}-08$ & $1.022 \mathrm{E}-03$ & $-3.184 \mathrm{E}-07$ & $-3.461 \mathrm{E}-03$ \\
\hline $\mathrm{e}$ & $-3.766 \mathrm{E}-08$ & $-3.178 \mathrm{E}-04$ & $-9.746 \mathrm{E}-10$ & $-2.856 \mathrm{E}-05$ & $3.951 \mathrm{E}-09$ & $8.420 \mathrm{E}-05$ & $-2.446 \mathrm{E}-10$ & $-7.393 \mathrm{E}-05$ & $1.752 \mathrm{E}-08$ & $1.839 \mathrm{E}-04$ \\
\hline
\end{tabular}




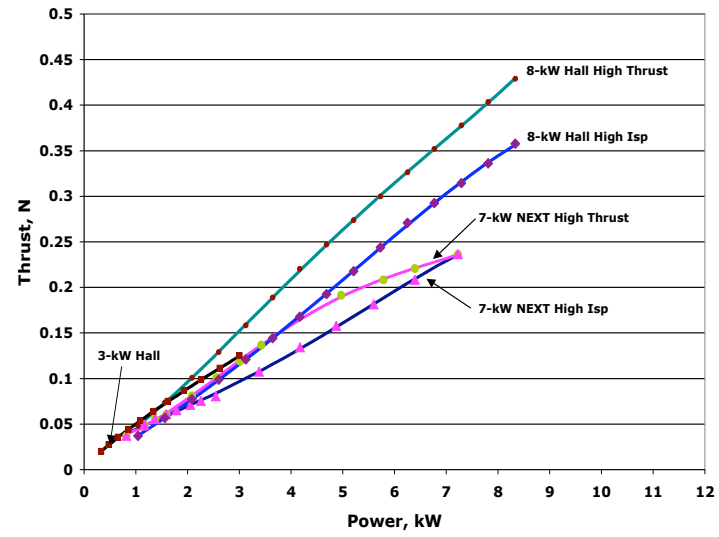

a) Thrust

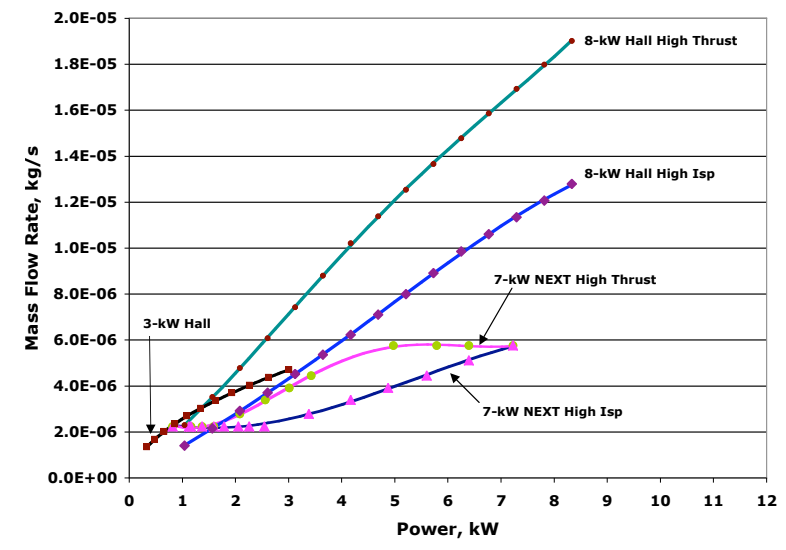

b) Mass flow rate

\section{Figure 4. 3-kW Hall, 8-kW Hall, and 7-kW NEXT thruster data and curve fits.}

From these curve fits, substantial differences in thrust and mass flow rates can be seen. Comparing thrust at 6$\mathrm{kW}$, the 3-kW Hall (2), 8-kW Hall, and NEXT generate thrust of roughly $250 \mathrm{mN}, 250$ or $310 \mathrm{mN}$, and 200 or 215 $\mathrm{mN}$, respectively. So, for $6-\mathrm{kW}$ of PPU power, the $3-\mathrm{kW}$ Hall can generate 16 or $25 \%$ more thrust than NEXT (depending on which NEXT throttling profile is simulated), and the $8-\mathrm{kW}$ Hall thruster can generate 16 or $55 \%$ more thrust (again, depending on which throttling profile is simulated for each thruster). The differences in mass flow rates are even more substantial. At 6-kW of PPU power, the 3-kW Hall (2) and 8-kW Hall have mass flow rates that are 65 or $95 \%$ and 65 or $295 \%$, respectively, higher than NEXT. These differences in thrust and mass flow rates are even larger at full power, and are due to the substantial differences in $\mathrm{I}_{\mathrm{sp}}$ that exist between the NEXT and Hall thrusters and are shown in Fig. 5. The peak $I_{s p}$ for the Hall thruster is less than 3,000 seconds, while the $I_{s p} s$ for NEXT are greater than 3,000 seconds for most of the operating range. Substantial differences in efficiency also exist and are shown in Fig. 6. Note that the system efficiency for NEXT is greater than the 3-kW Hall thruster for power above roughly $1.5 \mathrm{~kW}$ and greater than the 8-kW Hall thruster for essentially the entire operating range.

Despite these differences in specific impulse and efficiency, there are limited regions where the 8-kW Hall thruster and 7-kW NEXT produce the nearly the same thrust. For example, the NEXT high thrust throttling profile and the $8-\mathrm{kW}$ Hall high $\mathrm{I}_{\mathrm{sp}}$ throttling profile generate nearly the same thrust for power less than 4-kW, but the mass flow rate is higher for the $8-\mathrm{kW}$ Hall thruster when the power is greater than $2-\mathrm{kW}$.

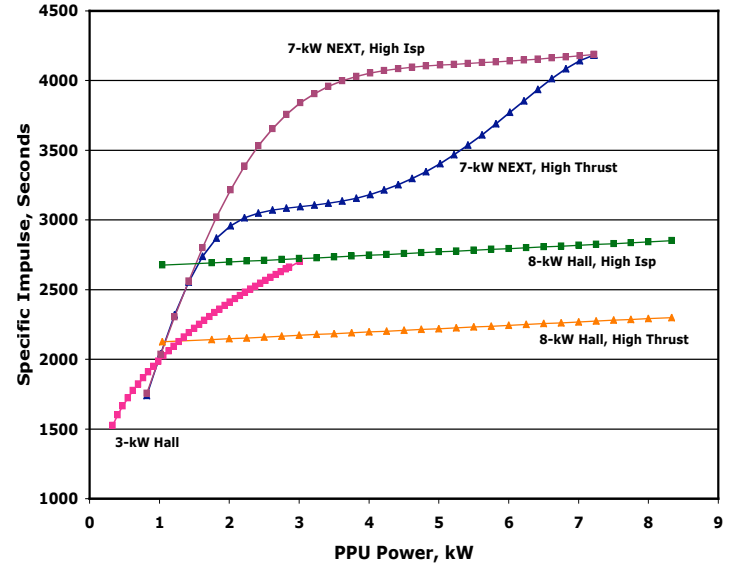

Figure 5. Specific impulse comparison across each thruster's operating range.

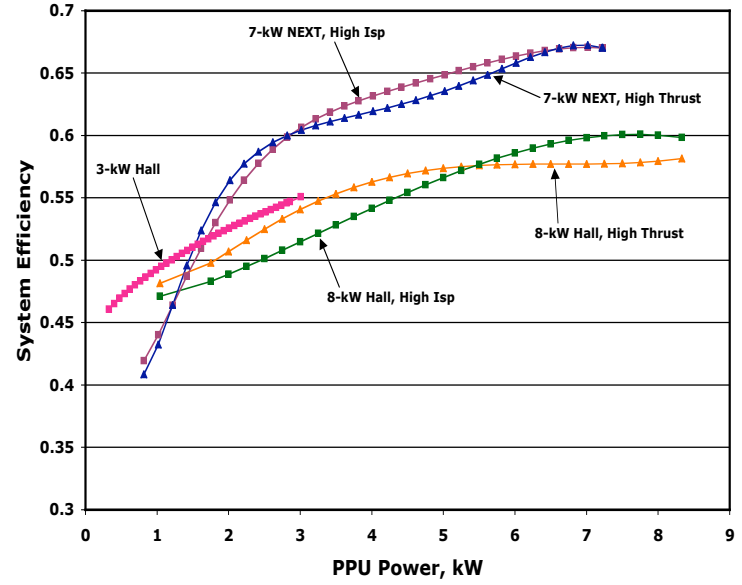

Figure 6. System efficiency comparison across each thruster's operating range. 
Just by looking over Fig. 5 and Fig. 6, one might be inclined to conclude that the performance, measured by NDM to target for a given trip time, of a higher specific impulse thruster, such as NEXT, would/should be superior to that of a lower specific impulse thruster, like Hall thrusters, for deep space missions. One might logically assert that the wet mass of the spacecraft using Hall thrusters would be greater than the wet mass of the spacecraft using NEXT, therefore the ratio of propellant mass to injected mass would be smaller for NEXT compared to Hall. While this statement is true, it does not necessarily mean that the NDM to target would be less for a higher thrust thruster. If the difference in injected mass is large enough between the two propulsion systems, this may overcome the difference in wet mass and the end result could be a higher final (dry) mass. Intuitively, one would expect the spacecraft that can produce more thrust throughout the entire trajectory to rely less on the capability of the launch vehicle for initial escape velocity. The question really becomes whether or not the difference in injected mass is enough to overcome the difference in the amount of propellant required.

\section{B. SEP Module Modeling}

Once the thruster performance has been modeled using two fourth order polynomials, a generic mass model of the entire SEP module was utilized. This mass model was based on the JPL Titan Orbiter Team X Study. ${ }^{19}$ A SEPTOP refinement enables a simplified model of the system masses to be input into SEPTOP via a series of coefficients. This refinement also enables a parametric analysis of payload and trip time to be accomplished efficiently. A top-level equation for the launch mass, $\mathrm{M}_{\text {Launch }}$, was previously developed for input into SEPTOP. ${ }^{11}$

$$
M_{\text {Launch }}=\alpha_{\text {power }} \times P+M_{\text {SEP-Fixed }}+M_{\text {payload }} \times\left(1+k_{\text {structure }}\right)+M_{\text {propellant }} \times\left(1+k_{\text {tankage }}\right)
$$

Stated in terms of the SEPTOP input variables this equation can be written as:

$$
m_{0}=\operatorname{alfa}(1) \times P_{0}+\operatorname{alfa}(2)+\operatorname{alfa}(7) \times(1+\operatorname{alfa}(8))+m_{p} \times(1+k t) .
$$

$\alpha_{\text {power }}, \mathrm{k}_{\text {structure, }}$ and $\mathrm{k}_{\text {tankage }}$ are parameters that model the rate at which their respective systems grow. $\mathrm{M}_{\mathrm{SEP}-\mathrm{Fixed}}$ is the fixed mass of the SEP module and includes the masses of the propulsion system, structure and cabling for the propulsion system, and thermal system. It is independent of the array size and propellant load. This parameter changes only when adding or removing a thruster (or PPU). Table 3 provides the input values for the above parameters for each electric propulsion system. The exact value of alfa(7), $\mathrm{M}_{\text {payload }}$, that is input into SEPTOP is unimportant. What is important is that a solution be found. After that, a time sweep is performed $\left(\mathrm{M}_{\text {payload }}\right.$ is now a free variable) and $\mathrm{M}_{\text {payload }}$ is simply solved for in a simple spreadsheet calculation. Table 4 provides the masses of the major components of the propulsion system. Examples of the complete SEP module mass breakdown are shown for each target planet in the results section, once the propellant load is determined.

\begin{tabular}{|c|c|c|c|}
\hline $\begin{array}{l}\text { Spacecraft } \\
\text { Assumptions [SEPTOP } \\
\text { Inputs] }\end{array}$ & 3-kW Hall & 8-kW Hall & 7-kW NEXT \\
\hline $\begin{array}{l}\text { Fixed mass [alfa( } 2)]\{3 \\
\text { thrusters/3 PPUs, } 4 \\
\text { thrusters/4 PPUs, } \\
\text { etc. }\}, \mathrm{kg}\end{array}$ & $\begin{array}{r}\mathrm{n} / \mathrm{a}, 376,423 \\
470,516\end{array}$ & $\begin{array}{r}519,625,731 \\
n / a, n / a\end{array}$ & $\begin{array}{r}511,627,742 \\
n / a, n / a\end{array}$ \\
\hline Payload [alfa(7)], kg & \multicolumn{3}{|c|}{$850-2,200$ depending on target planet and LV } \\
\hline $\begin{array}{l}\text { Payload Structure } \\
\text { Fraction [alfa(8)] }\end{array}$ & 0.085 & 0.085 & 0.085 \\
\hline $\begin{array}{l}\text { Tankage (includes } \\
\text { structure } \& 5 \% \\
\text { residual, } 3 \% \text { for NEXT) } \\
\text { [kt] }\end{array}$ & 0.175 & 0.175 & $\begin{array}{r}0.137(3 \% \\
\text { residuals) }\end{array}$ \\
\hline $\begin{array}{l}\text { Power System Specific } \\
\text { Mass [alfa(1)], } \mathrm{kg} / \mathrm{kW}\end{array}$ & 9.9 & 9.9 & 9.7 \\
\hline
\end{tabular}

Table 3 SEPTOP input parameters

\begin{tabular}{|c|c|c|c|c|c|c|}
\hline \multirow{2}{*}{ Componet } & \multicolumn{2}{|c|}{ 3-kW Hall } & \multicolumn{2}{|c|}{ 8-kW Hall } & \multicolumn{2}{|c|}{ 7-kW NEXT } \\
\hline & $\mathrm{CBE}$ & This Study & $\mathrm{CBE}$ & This Study & $\mathrm{CBE}$ & This Study \\
\hline Thruster & 3.6 & 3.9 & 10.0 & 10.0 & 12.4 & 13.3 \\
\hline PPU & 8.4 & 9.0 & 25.0 & 25.0 & 26.0 & 26.0 \\
\hline DCIU & \multicolumn{2}{|c|}{ incorporated into PPU } & \multicolumn{2}{|c|}{$\begin{array}{l}\text { incorporated into PPU/added } \\
3 \mathrm{~kg} \text { to total PPU mass }\end{array}$} & 5.65 & 5.2 \\
\hline Gimbal & 2.7 & 4.64 & 4.0 & 3.3 & 4.64 & 3.3 \\
\hline $\begin{array}{l}\text { Feed System } \\
\text { Fixed }\end{array}$ & 4.0 & 4.0 & 4.0 & 3.5 & 2.2 & 2.2 \\
\hline $\begin{array}{l}\text { Feed System Per } \\
\text { Thruster }\end{array}$ & 1.0 & 1.0 & 1.0 & 2.2 & 4.1 & 4.5 \\
\hline
\end{tabular}

Table 4 Major propulsion system masses (kg)

An additional SEPTOP refinement includes a modified model of the propulsion duty cycle. Typically, a 90-95\% propulsion duty cycle is simulated in the trajectory to account for very short coast periods for navigation and trajectory updates. This duty cycle reduces the available thrust and mass flow rate of the thruster. The modification that was made decoupled the thrust and mass flow rate duty cycle by adding $5 \%$ back to the mass flow rate duty cycle. This $5 \%$ of additional propellant is unavailable for thrust and simulates navigation and trajectory modeling errors and propellant feed system leakage that takes place throughout the entire thrusting portion of the trajectory. 
Simulating the trajectory in this manner affects how the propellant contingency mass is book kept. Instead of adding an $8-10 \%$ propellant contingency factor, which is typical for these types of simulations, to the total mass of the deterministic propellant (to account for leaks, restarts, filling error, residuals, etc.) only a 3-5\% propellant contingency factor is added to the mass of the deterministic propellant; the other $5 \%$ is assessed by SEPTOP as described above. The rest of the pertinent modeling assumptions are listed below.

- Mission Assumptions:

Jupiter epoch: 24 July 2009

Saturn epoch: 30 December 2010

Neptune epoch: 31 March 2010

Venus gravity assist

- Launch Vehicle Assumptions:

Delta IV 4450

Atlas V 551

$10 \%$ launch mass contingency

- SEP Stage Assumptions:

Single thruster operation permitted

Single thruster redundancy

$5 \%$ Xenon propellant contingency for flight errors (assessed by SEPTOP)

$5 \%$ Xenon propellant contingency for reserves (NEXT: $3 \%$ )

$90 \%$ propulsion duty cycle $(90 \%$ thrust $\& 95 \%$ mass flow rate)

$170 \mathrm{~W} / \mathrm{kg}$ solar arrays (NEXT: $174 \mathrm{~W} / \mathrm{kg}$ )

$5 \%$ mass added to solar arrays for power margin

$1 / \mathrm{R}^{2}$ array power

$2 \%$ per year array degradation

250 Watts supplied for housekeeping activities

Xenon tank mass fraction: $4.5 \%$ (NEXT: $3.4 \%$ )

Power and Thermal Structure: $16 \%$

Stage Cabling (not PPU): $6 \%$ of power mass

Tankage Mass Fraction includes structure (26\% dry) and Xenon propellant contingency for reserves

Spacecraft Adapter: $42 \mathrm{~kg}$

$30 \%$ dry mass contingency

\section{Launch Vehicle Modeling}

Performance data for the Delta IV 4450 and the Atlas V 551 was obtained from the Kennedy Space Center web site. ${ }^{20}$ This performance is modeled with an exponential curve fit and the coefficients and the reference altitude are input into SEPTOP. The form of the equation is given in Eq. (4) and assumes that the coefficients (A, B, and C) are all positive and that $\Delta \mathrm{V}_{\mathrm{L}}$ is less than $100 \mathrm{~km} / \mathrm{s}$.

$$
M_{\text {Launch }}=m_{0}=A e^{\frac{-\Delta V_{L}}{C}}-B
$$

The coefficients that were used in this study are given in Table 5; the launch vehicle performance curve fits are shown in Fig. 7. 
Table 5 SEPTOP launch vehicle coefficients and reference altitude

\begin{tabular}{lrrrr}
\hline \hline Launch Vehicle & $\mathrm{A}, \mathrm{kg}$ & $\mathrm{B}, \mathrm{kg}$ & $\mathrm{C}, \mathrm{km} / \mathrm{s}$ & $\mathrm{alt}, \mathrm{km}$ \\
\hline Delta IV 4450 & 19815.035 & 5491.56 & 4.7702 & 185 \\
Atlas V 551 & 21753.49 & 2085.33 & 3.3997 & 185 \\
\hline \hline
\end{tabular}

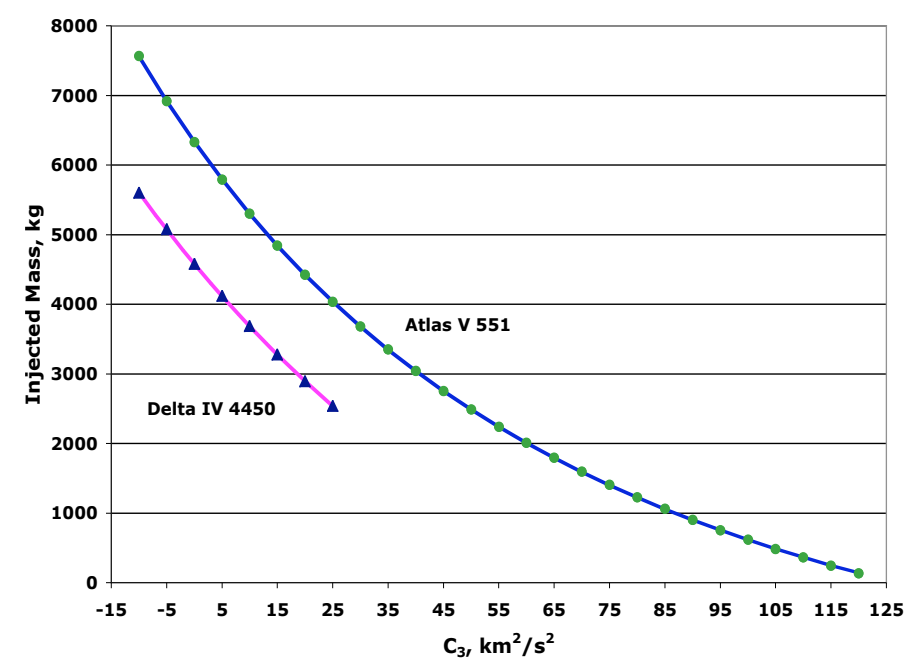

Figure 7. Launch vehicle performance data and curve fits.

\section{Trade Studies}

Any spacecraft sent on an interplanetary mission must first escape Earth's gravity well. For this analysis, an expendable launch vehicle provides the required velocity change to reach a hyperbolic orbit relative to Earth. The spacecraft builds up its heliocentric orbital energy by raising its aphelion. Thrust from the Hall thrusters efficiently lowers perihelion for a Venus flyby (modeled as an instantaneous event in SEPTOP). The spacecraft's velocity vector is redirected and its kinetic energy is substantially increased as a result of the flyby. This dramatic increase in kinetic energy as a result of the flyby is largely responsible for increasing the spacecraft's orbital energy, and relives the burden that would be placed on the propulsion system without the gravity assist. Once the required $\Delta \mathrm{V}$ is obtained, the thrusters are turned off and the SEP module is jettisoned. The spacecraft then starts its coast phase to reach the target planet.

A limited trade study was conducted on the launch vehicle and the BOL array power to see if the Hall performance trends varied with either of these parameters relative to the performance capability of NEXT. When the target planet was Saturn, the same solar array power was chosen for both launch vehicles. This way, the effect of a larger launch vehicle could be assessed when comparing performance results for different electric propulsion technologies. When Neptune was targeted, both power and launch vehicles were varied. For the mission to Jupiter, neither power nor launch vehicles were varied; Hall performance relative to NEXT on a smaller launch vehicle can be inferred from the Saturn and Neptune performance results.

Optimizing the combination of power and number of thrusters was not done in this study; an artificial limit was placed on the maximum number of operational thrusters. Understandably, more $3-\mathrm{kW}$ Hall thrusters are required for these deep space missions as compared to a 7 or $8-\mathrm{kW}$ thruster, especially for a trip to Neptune. The maximum and minimum number of operational thrusters considered for the 8-kW Hall and the 7$\mathrm{kW}$ NEXT were four and two, respectively. The maximum number of operational thrusters selected for the $3-\mathrm{kW}$ Hall was six; the minimum was

Table 6 Jupiter trade study parameters

\begin{tabular}{cccc}
\hline \hline & \multicolumn{3}{c}{ Atlas V 551 } \\
\cline { 2 - 4 } Thruster & $\begin{array}{c}\text { BOL array } \\
\text { power (1 AU), } \\
\text { kW }\end{array}$ & $\begin{array}{c}\text { Throttle profile } \\
\text { (high thrust or } \\
\text { high Isp) }\end{array}$ & $\begin{array}{c}\text { \# operating } \\
\text { thrusters }\end{array}$ \\
\hline 3-kW Hall & 15 & n/a & $3-6$ \\
8-kW Hall & 15 & both & $2-4$ \\
7-kW NEXT & 15 & both & $2-3$ \\
\hline \hline
\end{tabular}


three. All cases assumed a spare thruster and PPU for redundancy. Tables 6-8 summarize the trade-study parameters for each target planet.

Table 7 Saturn trade study parameters

\begin{tabular}{cccccccc}
\hline \hline & \multicolumn{3}{c}{ Delta IV 4450 } & & \multicolumn{2}{c}{ Atlas V 551 } \\
\cline { 2 - 3 } Thruster & $\begin{array}{c}\text { BOL array } \\
\text { power }(1 \mathrm{AU}), \\
\mathrm{kW}\end{array}$ & $\begin{array}{c}\text { Throttle profile } \\
\text { (high thrust or } \\
\text { high Isp) }\end{array}$ & $\begin{array}{c}\text { \# operating } \\
\text { thrusters }\end{array}$ & $\begin{array}{c}\text { BOL array } \\
\text { power (1 AU), } \\
\mathrm{kW}\end{array}$ & $\begin{array}{c}\text { Throttle profile } \\
\text { (high thrust or } \\
\text { high Isp) }\end{array}$ & $\begin{array}{c}\text { \# operating } \\
\text { thrusters }\end{array}$ \\
\hline 3-kW Hall & 18 & $\mathrm{n} / \mathrm{a}$ & $3-6$ & & 18 & $\mathrm{n} / \mathrm{a}$ & $3-6$ \\
8-kW Hall & 18 & both & $2-4$ & & 18 & both & $2-4$ \\
7-kW NEXT & 18 & both & $2-4$ & & 18 & both & $2-4$ \\
\hline \hline
\end{tabular}

Table 8 Neptune trade study parameters

\begin{tabular}{|c|c|c|c|c|c|c|}
\hline \multirow[b]{2}{*}{ Thruster } & \multicolumn{3}{|c|}{ Delta IV 4450} & \multicolumn{3}{|c|}{ Atlas V 551} \\
\hline & $\begin{array}{c}\text { BOL array } \\
\text { power (1 AU), } \\
\text { kW }\end{array}$ & $\begin{array}{c}\text { Throttle profile } \\
\text { (high thrust or } \\
\text { high Isp) }\end{array}$ & $\begin{array}{c}\text { \# operating } \\
\text { thrusters }\end{array}$ & $\begin{array}{c}\text { BOL array } \\
\text { power (1 AU), } \\
\text { kW }\end{array}$ & $\begin{array}{c}\text { Throttle profile } \\
\text { (high thrust or } \\
\text { high Isp) }\end{array}$ & $\begin{array}{c}\text { \# operating } \\
\text { thrusters }\end{array}$ \\
\hline 3-kW Hall & 30 & $\mathrm{n} / \mathrm{a}$ & 6 & 22 & $\mathrm{n} / \mathrm{a}$ & 6 \\
\hline 8-kW Hall & 30 & both & $2-4$ & 22 & both & $2-4$ \\
\hline 7-kW NEXT & 30 & both & $3-4$ & 22 & both & $3-4$ \\
\hline
\end{tabular}

\section{E. Results}

All net delivered masses reported in this section include the mass of all elements of the spacecraft (including its own power source), science payload, any necessary support structure and/or adapter(s). The propellant and SEP module masses have been subtracted out. Due to convergence issues sometimes associated calculus-of-variations based optimization codes, like SEPTOP, some of the time spans for a given combination of trade study parameters are significantly shorter than others; however, there was no difficulty in ascertaining the overall relative performance.

\section{Jupiter}

NDM to Jupiter as a function of trip time, number of operating Hall thrusters, and throttle profile (for the 8-kW Hall thruster) is shown in Fig. 8 and Fig. 9 for the 3-kW and 8-kW Hall thrusters, respectively.

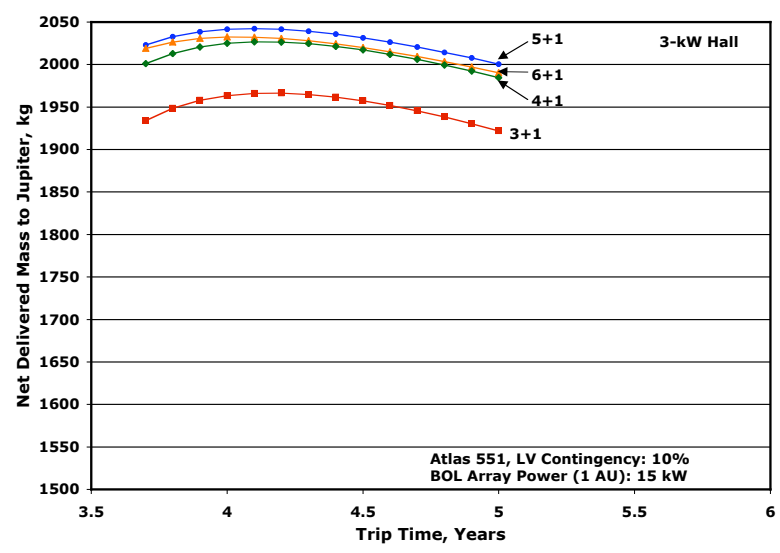

Figure 8. NDM to Jupiter as a function of trip time and number of operating thrusters for the spacecraft using 3-kW Hall thrusters.

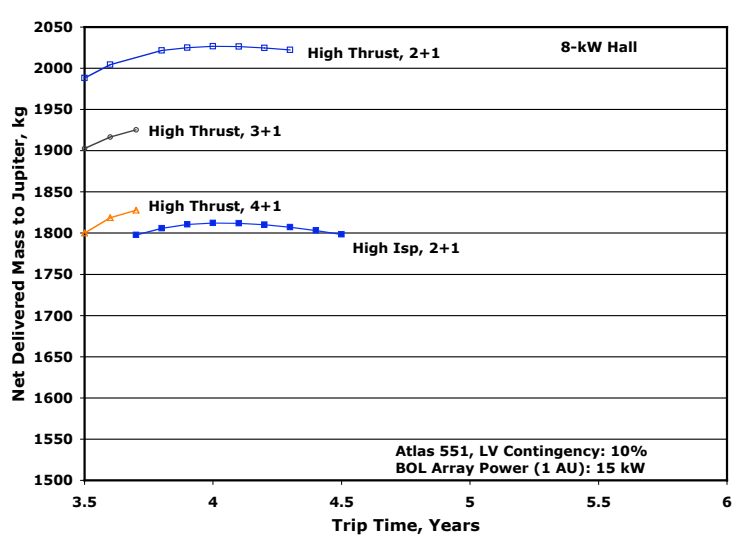

Figure 9. NDM to Jupiter as a function of trip time and number of operating thrusters for the spacecraft using 8-kW Hall thrusters. 
As Fig. 8 shows, the $5+1$ thruster configuration is the top performer and is selected for comparison with the capability of NEXT. Figure 9 shows that the $8-\mathrm{kW}$ Hall high thrust throttle profile outperforms the high $\mathrm{I}_{\mathrm{sp}}$ throttle profile; the $2+1$ thruster configuration yields the largest NDM and is selected for comparison with NEXT. Figure 10 shows the results for the NEXT propelled spacecraft. The largest masses delivered by the NEXT propelled spacecraft use the high thrust throttle profile. So, by looking at Fig. 8-10, one can conclude that the optimal specific impulses for this mission scenario are below 3,000 seconds. This fact is clearly indicated in Fig. 11, which shows the Hall and NEXT delivered mass and arrival $V_{\infty}$ comparison.

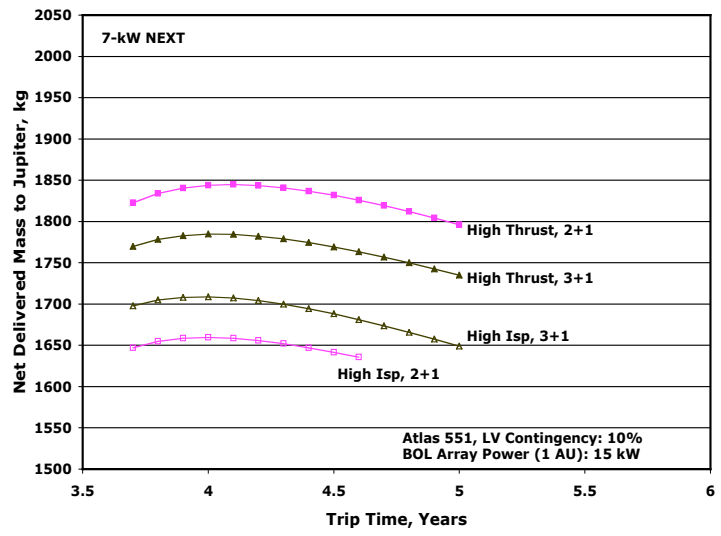

Figure 10. NDM to Jupiter as a function of trip time and number of operating thrusters for the spacecraft using 7-kW NEXT.

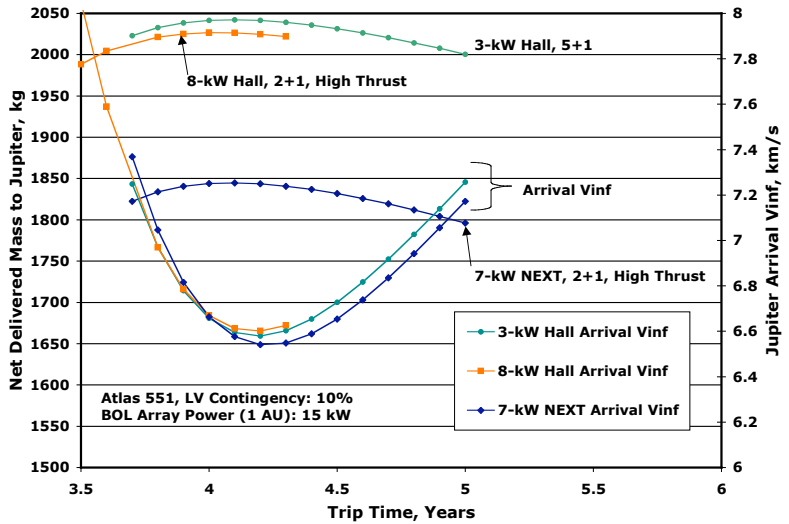

Figure 11. NDM to Jupiter as a function of trip time for the top performing Hall and NEXT propelled spacecraft.

Both versions of the Hall thruster deliver at least $175 \mathrm{~kg}$ more dry mass than NEXT for the trip times shown. Fewer 8-kW Hall thrusters are needed than $3-\mathrm{kW}$ Hall thrusters to deliver nearly the same mass. The spacecraft using Hall propulsion arrives with slightly less $V_{\infty}$ than the NEXT propelled spacecraft for transfer times less than four years. They have roughly the same arrival $V_{\infty}$ at four years, after which NEXT system provides slightly lower $V_{\infty}$.

Table 9 provides the breakdown of Hall and NEXT system masses for a 3.8-year transfer time. The Atlas launch vehicle injects an average of $23 \%$ more mass for the spacecraft using Hall thrusters than NEXT - more than enough to make up for the difference in wet mass. For the same transfer time, a trajectory and power and thruster variation profile is shown in Fig. 12 and Fig. 13, respectively, for the 8-kW Hall thruster.

Starting with two thrusters, the optimal thruster variation is 2-12-0 (short coast period)-2-1 thrusters. At the highest A.U. portion of the trajectory, one thruster provides the necessary thrust for lowering perihelion. For most of the trajectory the spacecraft flies with only a single thruster operating. Two thrusters operate at full power only once during the transfer-during the Venus flyby. Approximately 120 days after the gravity assist, the thrusters turn off and the SEP module is jettisoned, thus the spacecraft begins its coast phase to Jupiter.

The fact the spacecraft operates only one thruster at its high radial distances from the sun is not a given. A brief discussion on why a spacecraft would operate more than one thruster during this region may be worthwhile. Total PPU power for most of this region is less than $5-\mathrm{kW}$. Let's suppose that the spacecraft operates two thrusters for a portion of this region. This means it would have to split this power between those two thrusters. The spacecraft could operate both thrusters at $2-\mathrm{kW}$. The thrust produced by these electric thrusters is given by Eq. (5). ${ }^{21}$ At this lower power setting, the ratio of overall efficiency to specific impulse may or may not be larger than the same ratio at $4-\mathrm{kW}$. This means that it is very possible that two thrusters operating at $2-\mathrm{kW}$ each produce more

Table 9 Electric propulsion system masses for a 3.8-year transfer to Jupiter when launching on an Atlas V 551

\begin{tabular}{|c|c|c|c|}
\hline System/parameter & 3-kW Hall & 8-kW Hall & 7-kW NEXT \\
\hline \# of thrusters/PPUs & 6 & 3 & 3 \\
\hline NDM/Payload, kg & 2030 & 2022 & 1834 \\
\hline Attitude Control, $\mathrm{kg}$ & 3.0 & 3.0 & 3.0 \\
\hline Power, kg & 127.6 & 127.6 & 101.7 \\
\hline Propulsion, $\mathrm{kg}$ & 132.5 & 167.4 & 167.0 \\
\hline Structure, $\mathrm{kg}$ & 324.8 & 319.9 & 286.9 \\
\hline Cabling, kg & 54.0 & 49.4 & 45.0 \\
\hline Thermal, kg & 54.6 & 76.9 & 62.8 \\
\hline SEP dry, kg & 696.5 & 744.2 & 666.4 \\
\hline Contingency & $30 \%$ & $30 \%$ & $30 \%$ \\
\hline SEP dry w/contingencies & 951 & 1018 & 881 \\
\hline $\begin{array}{l}\text { Xe (includes } 5 \% \\
\text { contingency for nav } \\
\text { errors -assessed by } \\
\text { SEPTOP), } \mathrm{kg}\end{array}$ & 909 & 1018 & 503 \\
\hline Xe contingency (other) & $5 \%$ & $5 \%$ & $3 \%$ \\
\hline $\begin{array}{l}\text { Xe contingency (other), } \\
\mathrm{kg}\end{array}$ & 45 & 51 & 15 \\
\hline Total launch mass, $\mathrm{kg}$ & 3890 & 4057 & 3219 \\
\hline LV contingency & $10 \%$ & $10 \%$ & $10 \%$ \\
\hline $\mathrm{C} 3, \mathrm{~km}^{2} / \mathrm{s}^{2}$ & 21.3 & 19.0 & 31.5 \\
\hline $\mathrm{mp} / \mathrm{mo}$ & 0.25 & 0.26 & 0.16 \\
\hline
\end{tabular}


(or less) total thrust than one thruster operating a 4-kW. The spacecraft propelled by $8-\mathrm{kW}$ Hall thrusters operates a single thruster during this very power-limited region because the thrust generated is sufficient. It should not be assumed that any electric thruster would exhibit this characteristic; operating more than one thruster could generate more thrust and may be required.

In terms of the propellant mass fraction, NEXT is more efficient. However, this did not result in a higher final mass than the Hall propelled spacecraft. As a consequence of the relatively lower thrust produced by the NEXT propelled spacecraft, more energy is required from the launch vehicle relative to the Hall propelled spacecraft.

$$
T=\frac{2 \eta_{s y s} P}{g I_{s p}}, \mathrm{~N}
$$

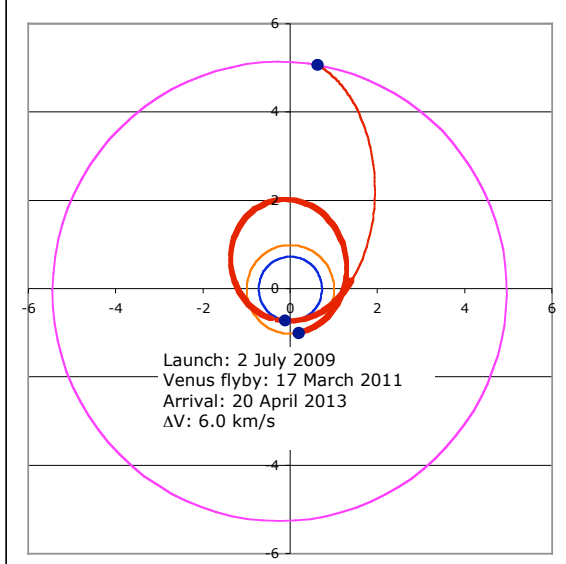

Figure 12. 3.8-year spacecraft trajectory to Jupiter using 8-kW Hall propulsion (bold curve depicts thrusting).

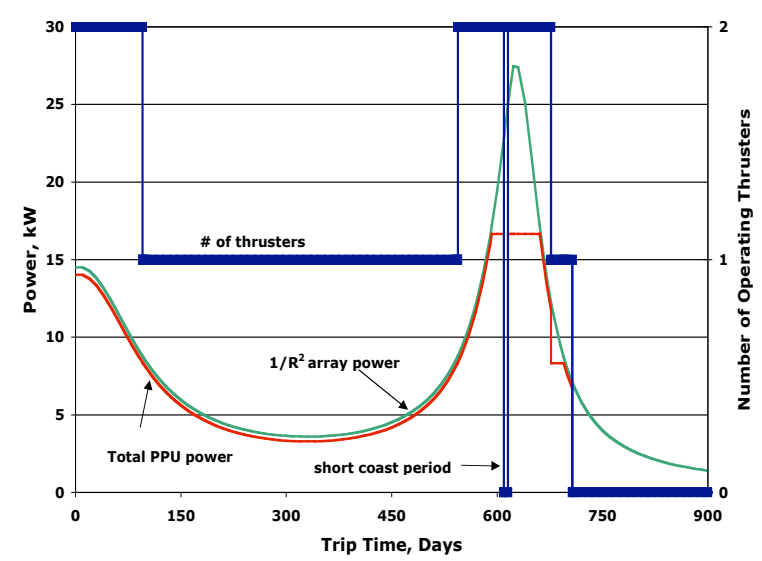

Figure 13. Spacecraft power and 8-kW Hall thruster variation history for a 3.8-year transfer to Jupiter.

\section{Jupiter Summary}

For the selected array power, launch vehicle and trajectory, the advanced Hall thrusters' specific impulses are more optimal than NEXT. Using Hall thrusters for the spacecraft's primary propulsion system enables at least an additional $175 \mathrm{~kg}$ to be delivered to Jupiter relative to the NEXT propelled spacecraft. The spacecraft using the 8$\mathrm{kW}$ Hall thrusters delivers slightly less mass than the 3-kW Hall propelled spacecraft; however, it does so with three less operating thrusters. The average throughput per thruster for this configuration is over $500 \mathrm{~kg}$.

\section{Saturn}

The trade-offs between the number of operating thrusters, throttling profile (when applicable), trip time, and NDM for the 3-kW Hall, 8-kW Hall and 7-kW NEXT when launching on a Delta IV 4450 are shown in Fig. 14-16. Figures 17-19 show the same trade studies when the spacecraft is launched on an Atlas V 551. BOL array power was set to $18-\mathrm{kW}$. 


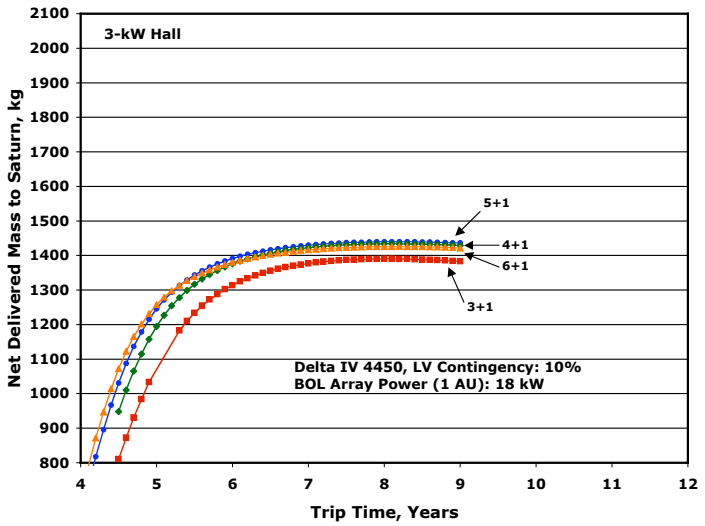

Figure 14. NDM to Saturn as a function of trip time and number of operating thrusters for the spacecraft using 3-kW Hall thrusters when launching on a Delta IV 4450.

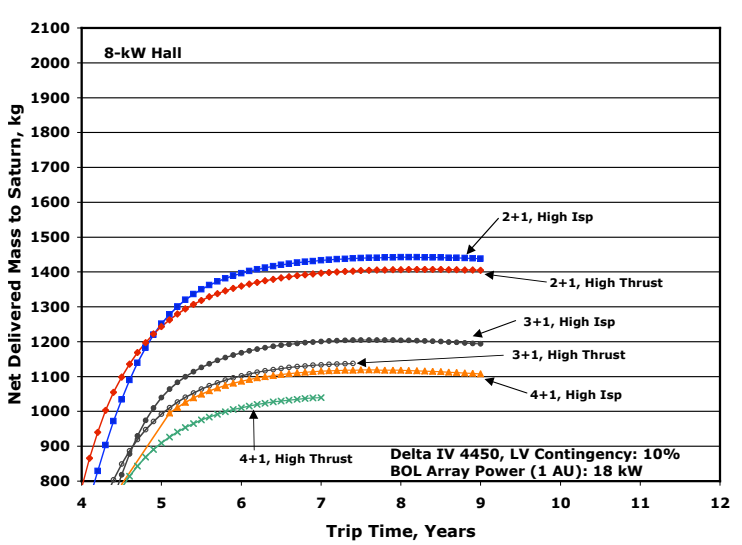

Figure 15. NDM to Saturn as a function of trip time, throttle profile, and number of operating thrusters for the spacecraft using 8-kW Hall thrusters when launching on a Delta IV 4450.

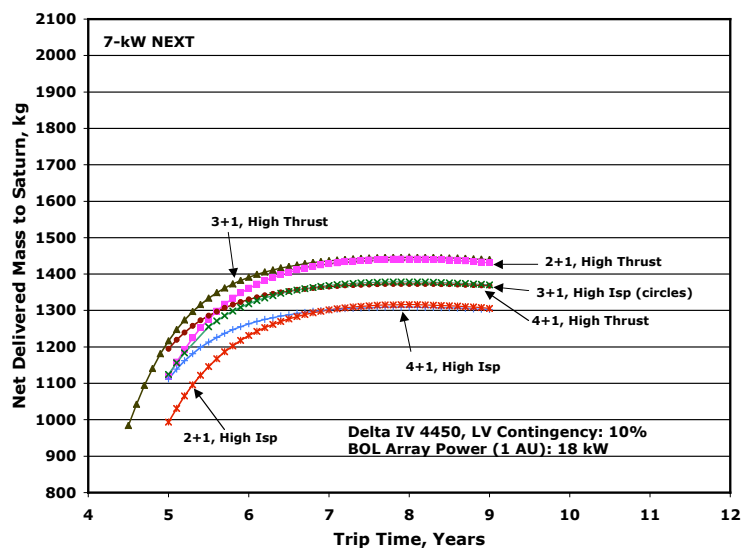

Figure 16. NDM to Saturn as a function of trip time, throttle profile, and number of operating thrusters for the spacecraft using 7-kW NEXT when launching on a Delta IV 4450.

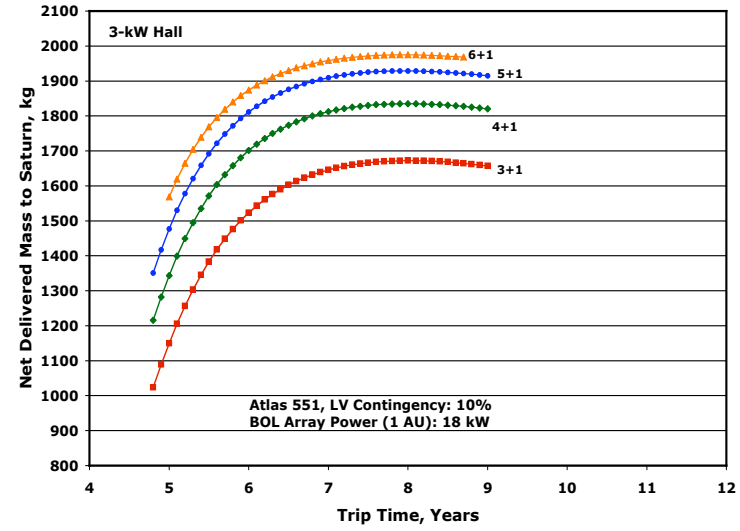

Figure 17. NDM to Saturn as a function of trip time and number of operating thrusters for the spacecraft using 3-kW Hall thrusters when launching on an Atlas V 551.

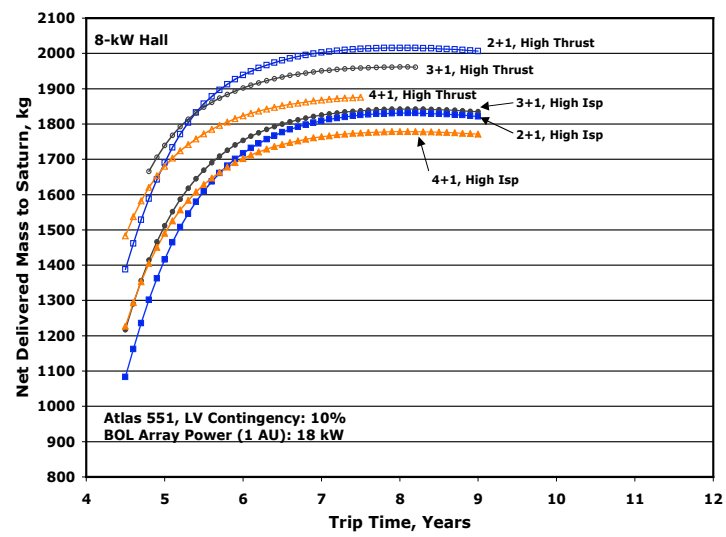

Figure 18. NDM to Saturn as a function of trip time, throttle profile, and number of operating thrusters for the spacecraft using 8-kW Hall thrusters when launching on an Atlas V 551.

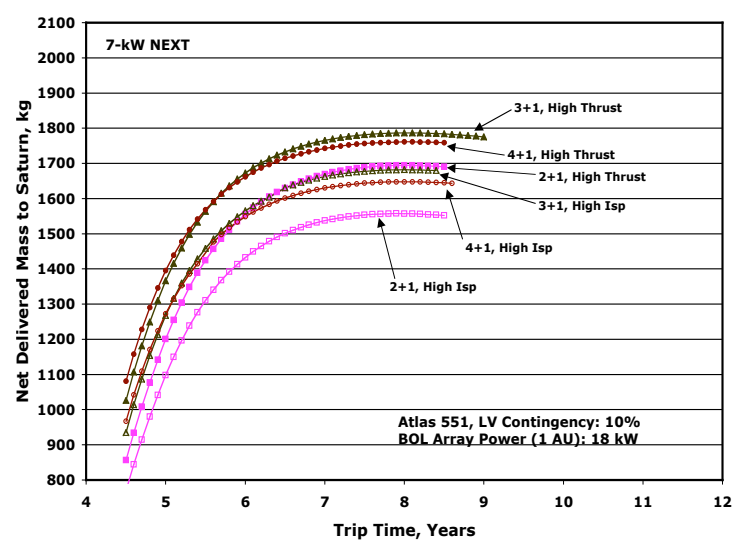

Figure 19. NDM to Saturn as a function of trip time, throttle profile, and number of operating thrusters for the spacecraft using 7-kW NEXT when launching on an Atlas V 551. 
By comparing the performance results of the spacecraft propelled by the 3-kW Hall thrusters when launched on the Delta IV 4450 or Atlas V 551 (Fig. 14 and Fig. 17), one can see greater sensitivity to the number of operating thrusters when launched on an Atlas V 551. Switching launch vehicles increases the NDM of the 5+1 thruster configuration by roughly $475 \mathrm{~kg}$.

The same comparison for the spacecraft using 8-kW Hall thrusters (Fig. 15 and Fig. 18) is interesting for two reasons. First, notice that when the spacecraft is launched on the Delta IV 4450, performance is primarily dependant on the number thrusters. This indicates a strong sensitivity to the dry mass. In fact, reducing the total number of thrusters from four to three results in an additional $200 \mathrm{~kg}$ of dry mass at Saturn. Secondly, notice that when the spacecraft is launched on the Atlas V 551, performance is primarily dependant on the throttle profile. The high thrust throttle profile yields the best results regardless of the total number of thrusters. This indicates a strong sensitivity to the thrusters' specific impulses. Roughly an additional $550 \mathrm{~kg}$ is delivered to Saturn when the spacecraft is launched on the Atlas V 551.

In regards to these same types of comparisons for the NEXT propelled spacecraft when launched on the Delta IV 4450 (Fig. 16), the NDM to Saturn is primarily dependant on the throttle profile for most of the transfer times. A $\mathrm{NDM}$ gain of roughly $60 \mathrm{~kg}$ is achieved just by changing the throttle profile from high $\mathrm{I}_{\mathrm{sp}}$ to high thrust. Figure 19 shows the same throttle profile sensitivity for the NEXT propelled spacecraft launched on an Atlas V 551. Switching launch vehicles results in roughly a $350 \mathrm{~kg}$ gain in the NDM to Saturn. Due to the relatively lower thrust of the NEXT propelled spacecraft, more of the capability of the Atlas launch vehicle is spent on a higher injection velocity. This results in a performance increase of roughly $125 \mathrm{~kg}$ and $200 \mathrm{~kg}$ less than what the 3-kW Hall and 8-kW Hall propelled spacecraft achieved when using a larger launch vehicle.

The top performance curves from Fig. 14-19 were selected for comparison and are shown in Fig. 20 and Fig. 21. When the spacecraft is launched on a Delta IV 4450, two operational 8-kW Hall thrusters and five operational 3-kW Hall thrusters deliver essentially the same mass to Saturn as two or three operational 7-kW NEXTs for transfer times greater than 7-years. For transfer times less than 7-years, the 8-kW Hall thruster offers the benefit of delivering nearly the same mass as NEXT with one fewer thruster than NEXT and three fewer thrusters than the 3-kW Hall.

Looking at Fig. 21, one can see that the Hall thrusters exhibit greater sensitivity to the launch vehicle performance capability. Just by switching launch vehicles, the differences in final masses between the two electric propulsion systems are substantial. The $8-\mathrm{kW}$ Hall thrusters enable the spacecraft to deliver roughly $200 \mathrm{~kg}$ more, while using one less thruster, to Saturn than the NEXT propulsion system. For the transfer times shown, average throughput per thruster for the $8-\mathrm{kW}$ Hall varies by $8 \%$ and never exceeds $635 \mathrm{~kg}$.

Tables 10 and 11 provide each electric propulsion system masses for a 5.7-year transfer to Saturn. For this same transfer time, a trajectory and thruster variation history profile is shown in Fig. 22 and Fig. 23 when the spacecraft utilizes 8-kW Hall thrusters and launches on an Atlas V 551.

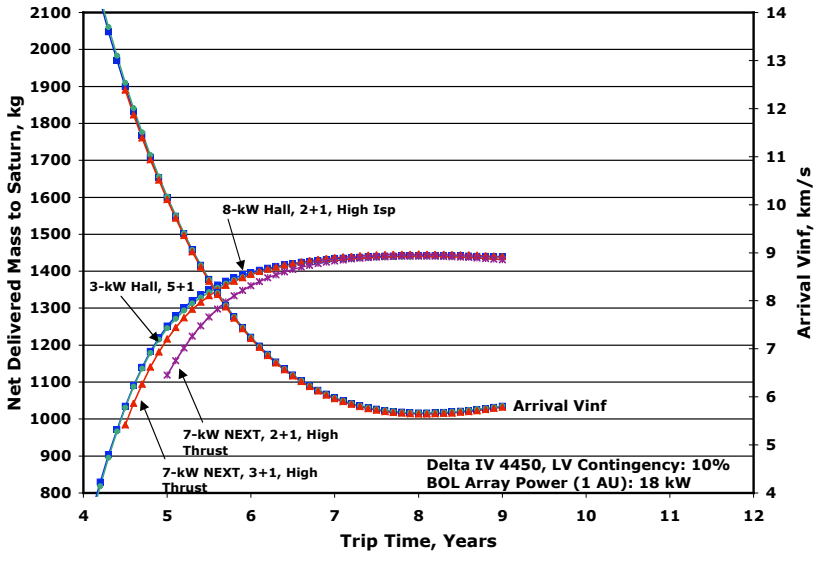

Figure 20. NDM to Saturn as a function of trip time for the top performing Hall and NEXT propelled spacecraft when launching on a Delta IV 4450.

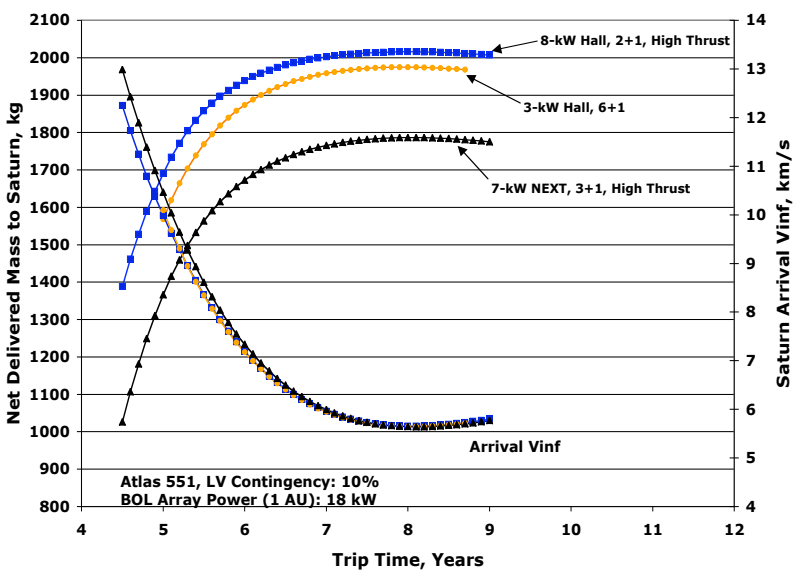

Figure 21. NDM to Saturn as a function of trip time for the top performing Hall and NEXT propelled spacecraft when launching on an Atlas V 551. 
Table 10 Electric propulsion system masses for a 5.7-year transfer to Saturn when launching on a Delta IV 4450

\begin{tabular}{lrrr}
\hline \hline System/parameter & 3-kW Hall & 8-kW Hall & 7-kW NEXT \\
\hline \# of thrusters/PPUs & 6 & 3 & 4 \\
& & & \\
NDM/Payload, kg & 1364 & 1373 & 1362 \\
& & & \\
Attitude Control, kg & 3.0 & 3.0 & 3.0 \\
Power, kg & 146.2 & 146.2 & 119.8 \\
Propulsion, kg & 131.8 & 158.9 & 218.6 \\
Structure, kg & 286.0 & 275.0 & 285.2 \\
Cabling, kg & 52.8 & 47.3 & 52.6 \\
Thermal, kg & 54.6 & 76.9 & 78.8 \\
SEP dry, kg & 674.3 & 707.3 & 758.0 \\
Contingency & $30 \%$ & $30 \%$ & $30 \%$ \\
SEP dry w/contingencies & 921 & 961 & 1005 \\
& & & \\
Xe (includes 5\% & & & \\
Contingency for nav & 894 & 837 & 637 \\
errors -assessed by & & & \\
SEPTOP), kg & & & \\
Xe contingency (other) & $5 \%$ & $5 \%$ & $3 \%$ \\
Xe contingency (other), & & & \\
kg & 45 & 42 & 19 \\
Total launch mass, kg & 3180 & 3171 & 3003 \\
LV contingency & $10 \%$ & $10 \%$ & $10 \%$ \\
C3, km ${ }^{2} / s^{2}$ & 11.8 & 11.9 & 14.3 \\
mp/m0 & 0.30 & 0.28 & 0.22 \\
\hline \hline
\end{tabular}

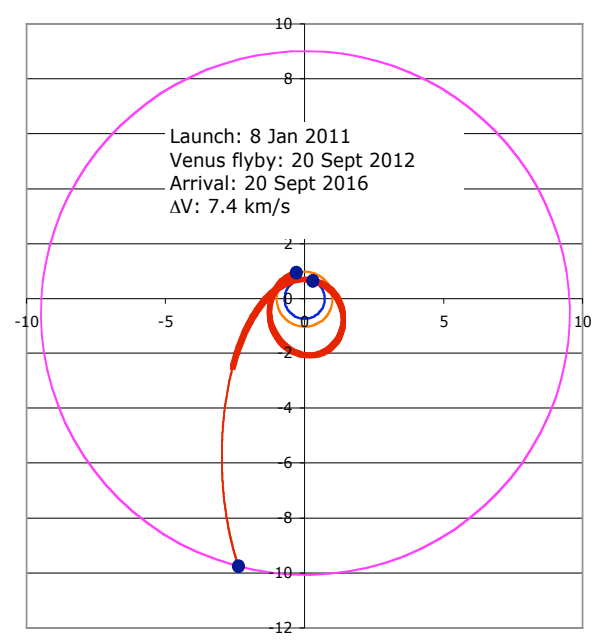

Figure 22. 5.7-year spacecraft trajectory to Saturn using 8-kW Hall propulsion (bold curve depicts thrusting).
Table 11 Electric propulsion system masses for a 5.7-year transfer to Saturn when launching on an Atlas V 551

\begin{tabular}{lrrr}
\hline \hline System/parameter & 3-kW Hall & 8-kW Hall & 7-kW NEXT \\
\hline \# of thrusters/PPUs & 7 & 3 & 4
\end{tabular}

NDM/Payload, kg

\begin{tabular}{rrr}
1817 & 1897 & 1615 \\
& & \\
3.0 & 3.0 & 3.0 \\
146.2 & 146.2 & 119.8 \\
157.1 & 179.1 & 220.1 \\
334.3 & 326.0 & 302.9 \\
60.2 & 51.6 & 53.8 \\
62.0 & 76.9 & 78.9 \\
762.9 & 782.8 & 778.5 \\
$30 \%$ & $30 \%$ & $30 \%$ \\
1048 & 1081 & 1033 \\
& & \\
& & \\
1132 & 1264 & 683 \\
& & \\
$5 \%$ & $5 \%$ & $3 \%$ \\
& & \\
57 & 63 & 20 \\
3997 & 4242 & 3331 \\
$10 \%$ & $10 \%$ & $10 \%$ \\
19.8 & 16.5 & 29.7 \\
0.30 & 0.31 & 0.21 \\
\hline & &
\end{tabular}

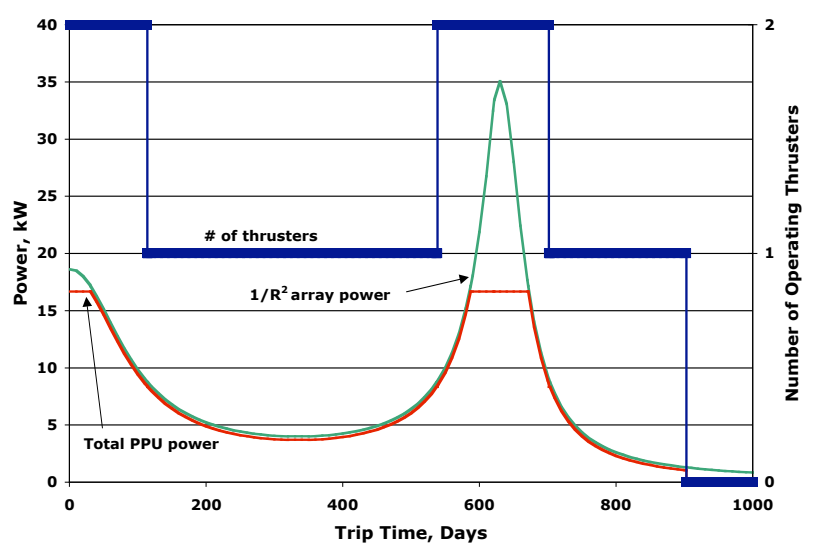

Figure 23. Spacecraft power and 8-kW Hall thruster variation history for a 5.7-year transfer to Saturn.

The spacecraft using NEXT has lower propellant mass fractions than the Hall propelled spacecraft when launched on either launch vehicle. However, this not does translate to better performance due to the difference in required launch energies $\left(\mathrm{C}_{3}\right)$ that are direct result of the relatively low thrust produced by the ion thrusters. A single 8-kW Hall thruster generates the necessary thrust to lower perihelion for a flyby of Venus as shown in Fig. 23. 


\section{Saturn Summary}

The NEXT and Hall propelled spacecraft deliver roughly the same mass to Saturn when launched on a Delta IV 4450. For transfer times less 7-years, one less 8-kW Hall thruster is required relative to NEXT.

Switching to a launch vehicle with an increased performance capability (and holding BOL solar array power constant) shows that the Hall thrusters' performance is more sensitive to the larger launch vehicle than the NEXT propulsion system for this mission scenario. A $200 \mathrm{~kg}$ delivered mass advantage for the Hall propelled spacecraft relative to the NEXT propelled spacecraft is achieved with the Atlas V 551. The 8-kW Hall thruster performed well for this mission scenario; it offers a substantial mass advantage with one fewer thruster than NEXT. The trade-off for this increased performance is a relatively high average throughput per thruster $(>600 \mathrm{~kg})$.

\section{Neptune}

The same kind of trade studies that were performed for a Saturn mission was performed for a Neptune mission with one exception: BOL solar array power was reduced roughly $25 \%$ when launched on the Atlas V 551 . This way, a trade-off between two different SEP mission architectures could be assessed. One mission architecture would require a relatively large BOL solar array combined with the performance of a relatively smaller launch vehicle, the other visa versa. The spacecraft performance results when launched on a Delta 4450 and an Atlas V 551 are shown in Fig. $24 \& 25$, and Fig. $26 \& 27$, respectively. Because of the higher power requirement for a larger $\Delta V$ mission to Neptune, the trade-off between the number of operational 3-kW Hall thrusters was not performed - only the performance of the $6+1$ thruster configuration was assessed.

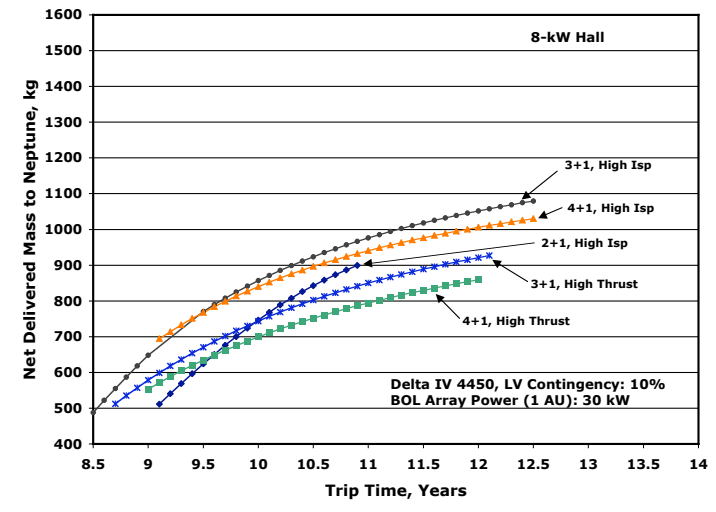

Figure 24. NDM to Neptune as a function of trip time, throttle profile and number of operating thrusters for the spacecraft using 8-kW Hall thrusters when launching on a Delta IV 4450.

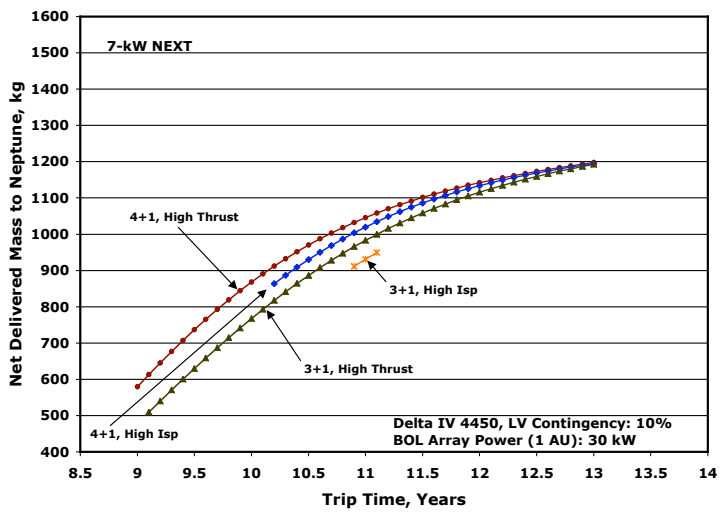

Figure 25. NDM to Neptune as a function of trip time, throttle profile and number of operating thrusters for the spacecraft using 7-kW NEXT when launching on a Delta IV 4450.

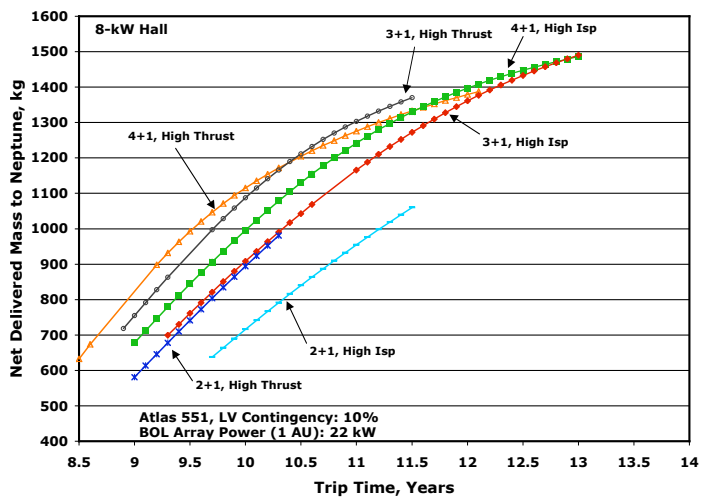

Figure 26. NDM to Neptune as a function of trip time, throttle profile and number of operating thrusters for the spacecraft using 8-kW Hall thrusters when launching on an Atlas V 551.

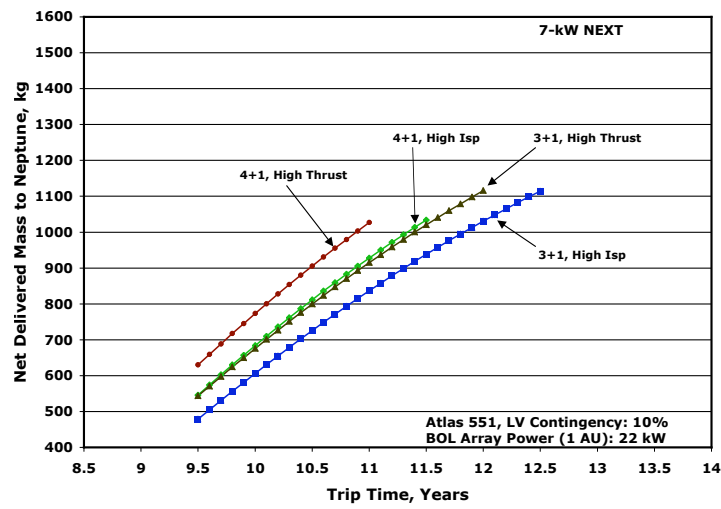

Figure 27. NDM to Neptune as a function of trip time, throttle profile and number of operating thrusters for the spacecraft using 7-kW NEXT when launching on an Atlas V 551. 
Although the optimal transfers time to Neptune are more than 13 years, as shown in Figures 24-27, past mission analysis work has focused on delivering an average payload of nearly $1,000 \mathrm{~kg}$ to Neptune in $10-11$ years. ${ }^{11,22}$

Figure 24 shows that the NDM to Neptune (Delta IV 4450 launcher) is primarily dependant on the 8-kW Hall throttle profile. The high $\mathrm{I}_{\mathrm{sp}}$ throttle profile yields a larger NDM than the high thrust profile. When the BOL array power is reduced from $30 \mathrm{~kW}$ to $22 \mathrm{~kW}$ and the launch vehicle changed from a Delta IV 4450 to an Atlas V 551 (Fig. 26), the Hall propelled spacecraft can reach Neptune several months sooner or deliver roughly an additional $300 \mathrm{~kg}$ in final mass for transfer times between 10-11 years by using the high thrust throttle profile. So, using a launch vehicle with a greater performance capability and reducing the array power resulted in a modest decrease of the mission's optimal specific impulses (the specific impulse differences between the high $\mathrm{I}_{\mathrm{sp}}$ and high thrust throttle profile).

The NEXT propelled spacecraft does not exhibit the same results. When the spacecraft is launched on the Delta IV 4450 or an Atlas V 551, performance is primarily dependant on the total number of thrusters; four operational thrusters enable a larger delivered mass than three. Better performance is achieved for the high thrust throttle profiles. The high $I_{s p}$ throttle profile may deliver a higher mass than the high thrust throttle profile for transfer times on the order of 13 years or longer. Although the performance capability of the Atlas V 551 is significantly more than the Delta IV 4450, the spacecraft's performance actually is reduced because of its sensitivity to power. This results in additional couple months of trip time or a rough average of $50 \mathrm{~kg}$ less mass at Neptune.

Once again, the best performance curves from Fig. 24-27 are selected for comparison and are shown in Fig. 28 and Fig. 29

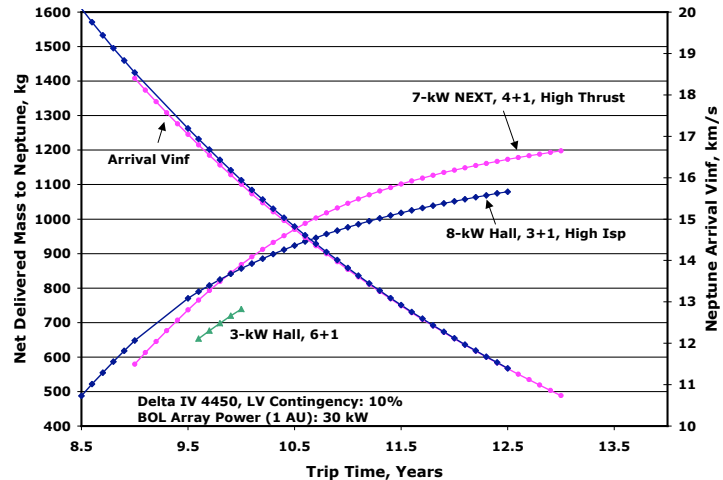

Figure 28. NDM to Neptune as a function of trip time for the top performing Hall and NEXT propelled spacecraft when launching on a Delta IV 4450.

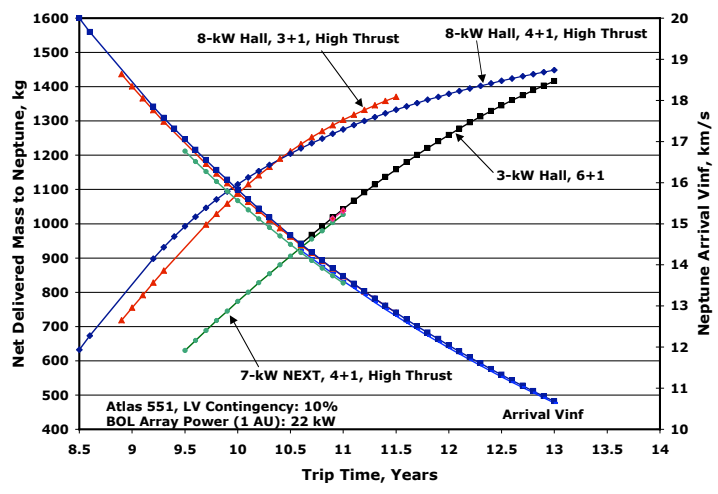

Figure 29. NDM to Neptune as a function of trip time for the top performing Hall and NEXT propelled spacecraft when launching on an Atlas V 551.

From viewing these two figures, one can see that the spacecraft propelled by Hall thrusters is more sensitive to the additional performance capability of the launch vehicle, and less sensitive to the BOL array power. In contrast, the NEXT propelled spacecraft shows greater sensitivity to BOL array power. When launched on a Delta IV 4450, NEXT outperforms the Hall system; the opposite is true when the launch vehicle is the Atlas V 551 and power is reduced. When the spacecraft is launched on the Atlas V 551, 8-kW Hall thrusters enable a trip time reduction on the order of a year or more or about a $300 \mathrm{~kg}$ gain in final mass at Neptune compared to the NEXT propelled spacecraft. Notice at this reduced power level, the performance of the $3-\mathrm{kW}$ Hall thrusters and NEXT are nearly identical.

Because the maximum power of the 8-kW Hall and 7-kW NEXT differ by $\sim 1-\mathrm{kW}$, four operational 8-kW Hall can process an additional 4-kW of power relative to NEXT inside 1 A.U. To assess what kind of effect this additional available power would have on performance, the maximum power for the 8-kW Hall thrusters was constrained to $7.3-\mathrm{kW}$ for the $4+1$, Atlas V 551 case. The mass delivered to Neptune for this case was reduced by $3 \%$. This small performance decrease is consistent with the performance shown by the 3-kW Hall thrusters; its mass delivery capability is nearly the same as NEXT while the maximum power processed is $11-\mathrm{kW}$ less than NEXT (inside 1 A.U.).

A SEP mass breakdown for a 10.7-year transfer to Neptune when launched on a Delta IV 4450 is shown in Table 12. Table 13 provides the same mass breakdown when the spacecraft is launched on an Atlas V 551. When the NEXT propelled spacecraft is launched on the Atlas V 551, the increment in required launch energy is large enough 
that the launch vehicle actually injects less mass than the Delta IV 4450. This is because 22-kW is far from its optimal power level. In contrast, the total thrust produced by the Hall propelled spacecraft is sufficient to handle this reduction in power.

Figure 30 shows the trajectory profile for a 10.7-year transfer to Neptune and Fig. 31 provides the corresponding power and thruster variation history. All three thrusters are turned on only for two relatively short periods-at the beginning of the trajectory and during the Venus flyby. Dual thruster operations are used primarily for throttling from three to two thrusters and visa versa.

Table 12 Electric propulsion system masses for a 10.7-year transfer to Neptune when launching on a Delta IV 4450

\begin{tabular}{|c|c|c|}
\hline System/parameter & 8-kW Hall & 7-kW NEXT \\
\hline \# of thrusters/PPUs & 4 & 5 \\
\hline NDM/Payload, kg & 946 & 1004 \\
\hline Attitude Control, kg & 3.0 & 3.0 \\
\hline Power, kg & 220.3 & 192.2 \\
\hline Propulsion, kg & 215.4 & 275.1 \\
\hline Structure, kg & 295.4 & 305.5 \\
\hline Cabling, kg & 60.2 & 65.1 \\
\hline Thermal, kg & 97.1 & 94.8 \\
\hline SEP dry, kg & 891.4 & 935.7 \\
\hline Contingency & $30 \%$ & $30 \%$ \\
\hline SEP dry $\mathrm{w} /$ contingencies & 1221 & 1244 \\
\hline $\begin{array}{l}\text { Xe (includes } 5 \% \\
\text { contingency for nav } \\
\text { errors -assessed by } \\
\text { SEPTOP), kg }\end{array}$ & 1240 & 909 \\
\hline Xe contingency (other) & $5 \%$ & $3 \%$ \\
\hline $\begin{array}{l}\text { Xe contingency (other), } \\
\text { kg }\end{array}$ & 62 & 27 \\
\hline Total launch mass, kg & 3407 & 3156 \\
\hline LV contingency & $10 \%$ & $10 \%$ \\
\hline $\mathrm{c} 3, \mathrm{~km}^{2} / \mathrm{s}^{2}$ & 8.8 & 12.1 \\
\hline $\mathrm{mp} / \mathrm{mo}$ & 0.38 & 0.30 \\
\hline
\end{tabular}

Table 13 Electric propulsion system masses for a 10.7-year transfer to Neptune when launching on an Atlas V 551

\begin{tabular}{lrrr}
\hline \hline System/parameter & 3-kW Hall & 8-kW Hall & 7-kW NEXT \\
\hline \# of thrusters/PPUs & 7 & 4 & 5 \\
& & & \\
NDM/Payload, kg & 965 & 1252 & 956 \\
& & & \\
Attitude Control, kg & 3.0 & 3.0 & 3.0 \\
Power, kg & 170.9 & 170.9 & 143.9 \\
Propulsion, kg & 162.1 & 232.9 & 269.3 \\
Structure, kg & 290.3 & 322.2 & 287.5 \\
Cabling, kg & 59.3 & 59.9 & 60.8 \\
Thermal, kg & 62.0 & 97.1 & 94.8 \\
SEP dry, kg & 747.6 & 886.0 & 859.3 \\
Contingency & $30 \%$ & $30 \%$ & $30 \%$ \\
SEP dry w/contingencies & 1034 & 1232 & 1139 \\
& & & \\
Xe (includes 5\% & & & \\
contingency for nav & 1238 & 1612 & 745 \\
Serrors -assessed by & & & \\
Xe contingency (other) & $5 \%$ & $5 \%$ & $3 \%$ \\
Xe contingency (other), & & & \\
kg & 62 & 81 & 22 \\
Total launch mass, kg & 3236 & 4096 & 2840 \\
LV contingency & $10 \%$ & $10 \%$ & $10 \%$ \\
C3, km ${ }^{2}$ s $^{2}$ & 31.2 & 18.5 & 38.1 \\
mp/m0 & 0.40 & 0.41 & 0.27 \\
\hline \hline
\end{tabular}

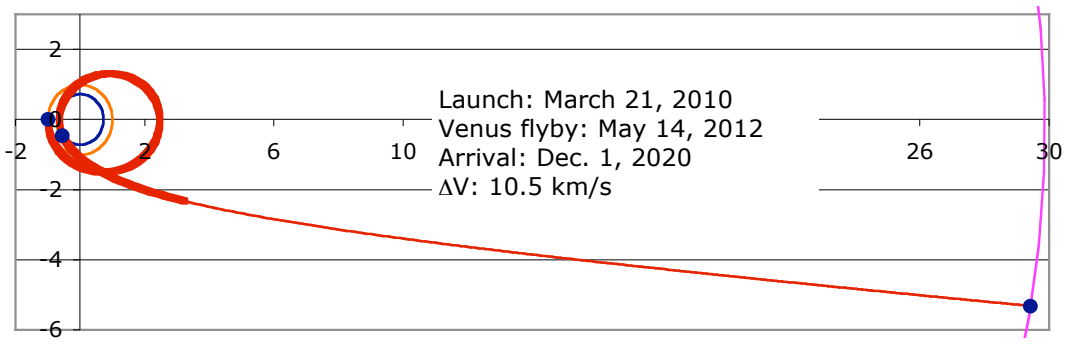

Figure 30. 10.7-year spacecraft trajectory to Neptune using 8-kW Hall propulsion (bold curve depicts thrusting). 


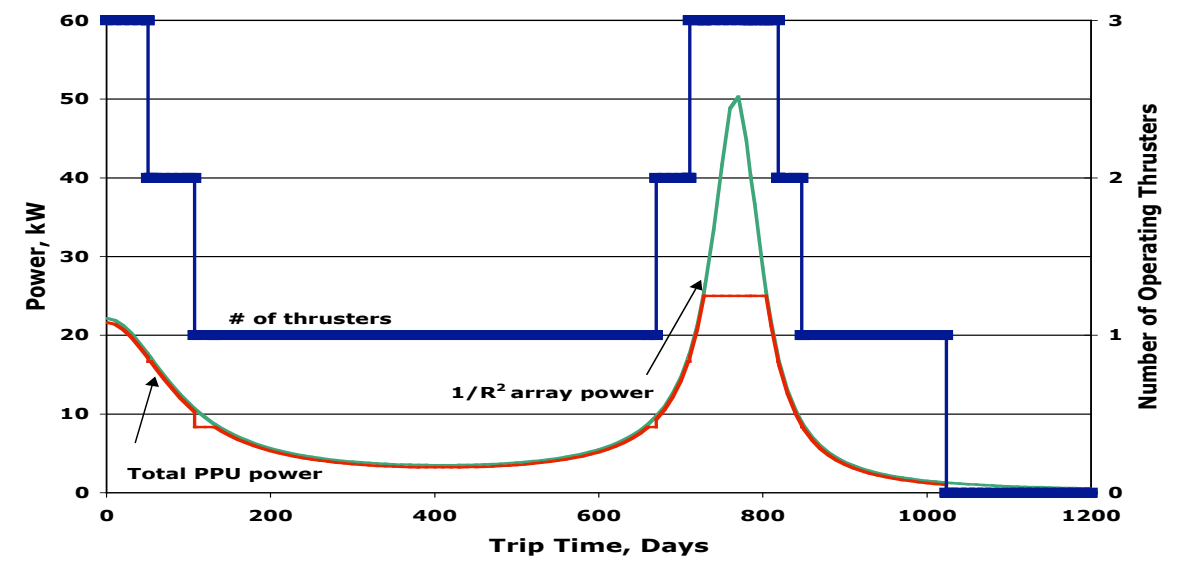

Figure 31. Spacecraft power and 8-kW Hall thruster variation history for a 10.7-year transfer to Neptune.

\section{Neptune Summary}

When launched a Delta IV 4450, the NEXT propelled spacecraft delivers $\sim 30 \mathrm{~kg}$ more than the Hall propelled spacecraft for 10-11 year transfer times. For longer trip times, the mass advantage increases.

Selecting a launch vehicle with more performance capability and decreasing solar array power by roughly $25 \%$ reveals something important: an electric thruster that produces relatively higher thrust can enable a reduction in solar array power and the number of operational thrusters. The thrust produced by NEXT is simply not high enough to take advantage of this; therefore, the Hall propelled spacecraft outperforms the NEXT propelled spacecraft by roughly $300 \mathrm{~kg}$ for $10-11$ year transfer times.

This result is important because if the delivered mass requirement grows significantly enough to necessitate the use of a launch vehicle with more performance capability, an electric thruster that produces relatively more thrust could enable a reduction in power and required thrusters that a higher specific impulse thruster could not. In fact, since the time this analysis was performed, a detailed Neptune mission trade study has established a SEP baseline trajectory that must deliver $22,230 \mathrm{~kg}$ to Neptune's SOI- over a $100 \%$ mass growth from previous analysis. ${ }^{23}$ To meet this high mass requirement, that study used two gravity assists, a Delta IV $4050 \mathrm{H}$ launch vehicle, and five operational NEXT thrusters that use the high $\mathrm{I}_{\mathrm{sp}}$ throttle profile.

\section{Conclusion}

This study is believed to be the first of its kind in that it assessed the performance of deep space SEP missions using next generation Hall thrusters for primary propulsion applications - mission scenarios previously reserved for thrusters that generate higher specific impulses. In order to access the performance of a spacecraft using advanced Hall thrusters as its primary propulsion system, trade-studies were conducted on mission parameters such as thruster count, throttle profile, and launch vehicle to identify the spacecraft configuration that delivered the largest mass for a range of trip times to each of three target planets: Jupiter, Saturn, and Neptune. These same trade-studies were conducted for a spacecraft that utilized the ASOA NEXT ion system for its primary propulsion system and the top performing spacecraft configuration was also identified. A relative comparison was made between the existing NEXT system and the projected next generation Hall primary propulsion systems.

Results in this study show that for four of out the five mission scenarios assessed, a spacecraft propelled by an advanced Hall thruster (of the type under development) offered at least one of the following benefits relative to the existing higher $\mathrm{I}_{\mathrm{sp}} \mathrm{NEXT}$ :

(1) Better performance - larger payload or shorter flight time;

(2) Fewer thrusters;

(3) Less BOL array power. 
These promising advantages of advanced Hall thrusters should be realized in the context that every mission is unique, and that this study only provides a snapshot of the relative performance. Because each mission is unique, it will have specific science objectives and cost-caps that will strongly affect important parameters such as the launch vehicle and array power. And as this study shows, the combination of launch vehicle and array power has dramatic consequences when comparing the performance of the advanced Hall thrusters and the ASOA NEXT ion system. One should not assume a priori that advanced Hall thrusters would offer one or more of these benefits for every deep space mission; more analyses needs to be performed.

Having hopefully placed these results in the proper context, several important conclusions can be drawn:

(1) The optimal specific impulses for SEP deep space missions of the kind that this study considers are determined by various mission design parameters including destination, required payload, power, and launch vehicle. However, this study finds that advanced Hall thrusters offer the more optimal $\mathrm{I}_{\mathrm{sp}} \mathrm{s}$ for most of the mission scenarios considered.

(2) Increased launch vehicle performance capability tends to significantly lower these missions' optimal specific impulse. As a result, a mission designer could choose to take on the added propellant load that is inherent with a higher thrust system, but have enough of a performance margin to reduce power and therefore cost.

(3) Higher specific impulses do not necessarily translate to better performance. Often, better performance is achieved with the higher thrust throttle profile of NEXT rather than the high $\mathrm{I}_{\mathrm{sp}}$ throttle profile.

(4) The relatively higher thrust generated by the Hall thrusters enables a reduction in solar array power requirements that a higher $\mathrm{I}_{\mathrm{sp}}$ thruster cannot.

(5) For missions to Jupiter and beyond, the $3-\mathrm{kW}$ Hall thruster is not appropriate because it requires several more operational thrusters than the 7-kW NEXT and 8-kW Hall. Additionally, operation at power levels below $3 \mathrm{~kW}$ is not driven by the available power from the sun.

(6) Increased lifetime capabilities are essential for optimal performance of the $8-\mathrm{kW}$ Hall thrusters. Average throughput per thruster requirements is on the order of $400-600 \mathrm{~kg}$.

(7) The mission benefits provided by advanced Hall thrusters may warrant the future development of propulsion systems based on this emerging technology if thruster throughput can be adequately addressed.

These findings are important because if the advanced Hall thruster throughput can be adequately addressed, the application of advanced Hall thrusters to deep space SEP missions potentially enables a reduction in mission class. For example, if the science/payload objectives of a Flag Ship class mission can be met with fewer thrusters and less array power, the resulting cost-savings may be substantial enough that the mission becomes a New Frontiers class mission. Launch vehicle costs would also have to be considered. Of course, cost analyses would need to be performed, and more mission analyses would need to be done, but the potential exists.

Other possible advanced Hall thruster applications include using the Hall thrusters to spiral out from the Earth's gravity well and for the heliocentric transfer. This scenario would reduce the size of the launch vehicle required and the complexity associated with carrying a different propulsion system for the heliocentric transfer. However, spare thrusters may be needed if throughput requirements become an issue.

In light of this analysis, one must wonder what the results would be of a similar trade-study for SEP missions in the inner solar system: missions such as a comet surface sample return (CSSR) or another type of small body rendezvous. These missions may or may not require a gravity assist. The BOL array power requirements may be substantially less than missions to the outer solar system. The launch vehicle performance capability that is required to enable these types of missions to small bodies may be less than missions to the outer solar system. Despite these variants, recent mission analyses with the objective of assessing the applicability of electric thrusters such as NEXT and Hall for Discovery class missions have shown similar results: advanced Hall thrusters can offer a performance advantage relative to NEXT (and NSTAR). ${ }^{24}$ Additionally, that study found that advanced Hall thrusters could offer a cost benefit.

As a final closing remark, although this study showed substantial performance benefits for advanced Hall thrusters relative to NEXT, the technologies are at different maturity levels. The advanced Hall thrusters are only at TRL 4, and have not yet been fully validated. Substantiation of these performance benefits requires further technical development. 


\section{References}

${ }^{1}$ Gulczinski, F. S., Analysis of Hall-Effect Thrusters and Ion Engines for Orbit Transfer Missions," $32^{\text {nd }}$ AIAA/ASME/SAE/ASEE Joint Propulsion Conference, AIAA 96-2973, July 1-3, 1996.

${ }^{2}$ Leifer, S., and Noca, M.,"Negative C3 Launch Options for Solar System Exploration,” AIAA 98-3925, 1998.

${ }^{3}$ Gulczinski, F. S., Spores, R. A., and Stuhlberger, J., "In-Space Propulsion," AIAA/ICAS International Air and Space Symposium and Exposition: The Next 100 Years," AIAA 2003-2588, July 14-17, 2003.

${ }^{4}$ Oleson, S. R., and Sankovic, J. M., "Electric Propulsion for Low Earth Orbit Constellations,” NASA TM-208821, 1998.

${ }^{5}$ Gefert, L. P., Hack, K. J., and Kerslake, T. W., Options for the Human Exploration of Mars using Solar Electric Propulsion, AIP Conference Proceedings, No. 458, pp 1275-1280, STAIF-99, Nov. 1999.

${ }^{6}$ Brophy, J.R., and Noca, M., "Electric Propulsion for Solar System Exploration,” Journal of Propulsion and Power, Vol. 14, No. 5, 1998, pp. $700-707$.

${ }^{7}$ Oleson, S. R., and Sankovic, J. M., “Advanced Hall Electric Propulsion for Future In-Space Transportation,” NASA TM$210676,2001$.

${ }^{8}$ Oleson, S. R., "Mission Advantages of Constant Power, Variable Isp Electrostatic Thrusters,", 36 ${ }^{\text {th }}$ AIAA/ASME/SAE/ASEE Joint Propulsion Conference, AIAA 2000-3413, July 16-19, 2000.

${ }^{9}$ Fiehler, D., and Oleson, S., “A Comparison of Electric Propulsion Systems for Mars Exploration," $39^{\text {th }}$ AIAA/ASME/SAE/ASEE Joint Propulsion Conference, AIAA 2003-4574, July 20-23, 2003.

${ }^{10}$ Oh, D., Benson, S., Witzberger, K., and Cupples, M., "Deep Space Mission Applications for NEXT: NASA's Evolutionary Xenon Thruster," $40^{\text {th }}$ AIAA/ASME/SAE/ASEE Joint Propulsion Conference, AIAA 2004-3806, July 11-14, 2004.

${ }^{11}$ Oleson, S., Gefert, L., Benson, S., Patterson, M., Noca, M., Sims, J., "Mission Advantages of NEXT: NASA's Evolutionary Xenon Thruster," $38^{\text {th }}$ AIAA/ASME/SAE/ASEE Joint Propulsion Conference, AIAA 2002-3969, July 7-10, 2002.

${ }^{12}$ Integrated Technology Plan for the Civil Space Program, JCM-7410, March 17, 1991.

${ }^{13}$ Oleson, S., and Myers, R., "Launch Vehicle and Power Level Impacts on Electric GEO Insertion," $32^{\text {nd }}$ AIAA/ASME/SAE/ASEE Joint Propulsion Conference, AIAA 1996-2978, July, 1996.

${ }^{14}$ Manzella, D., Jacobson, D., and Jankovsky, R., "High Voltage SPT Performance,", $37^{\text {th }}$ AIAA/ASME/SAE/ASEE Joint Propulsion Conference, AIAA 2001-3774, July 2001.

${ }^{15}$ Hofer, R., and Gallimore, A., "Efficiency Analysis of a High-Specific Impulse Hall Thruster," $40^{\text {th }}$ AIAA/ASME/SAE/ASEE Joint Propulsion Conference, AIAA 2004-3602, July, 2004.

${ }^{16}$ Sengupta, A., Brophy, J., Anderson, J., Garner, C., Banks, B., and de Groh, K., "An Overview of the Results from the 30,000 Hr Life Test of Deep Space 1 Flight Spare Ion Engine," 40 ${ }^{\text {th }}$ AIAA/ASME/SAE/ASEE Joint Propulsion Conference, AIAA 2004-3608, July 2004.

${ }^{17}$ de Grys, K., Fisher, J., Wilson, F., Beal, B., Dimicco, J., and Khayms, V., "4.5 KW Hall Thruster System Qualification Status," AIAA 2004-3603, 40 ${ }^{\text {th }}$ AIAA/ASME/SAE/ASEE Joint Propulsion Conference, July, 2004.

${ }^{18}$ Polk, J., Kakuda, R, Anderson, J., Brophy, J., Rawlin, V., Patterson, M., Sovey, J., and Hamley, J., "Performance of the NSTAR Ion Propulsion System on the Deep Space One Mission," AIAA 2001-96, Jan., 2001.

${ }^{19}$ Advanced Projects Design Team (Team X), Titan Orbiter 2003-10, Report ID \#658, October 7,9,10, 2003.

${ }^{20} \mathrm{http}: / /$ elvperf.ksc.nasa.gov/elvMap/index.html

${ }^{21}$ Wertz, J. R., and Larson, W. J., Space Mission Analysis and Design, $3^{\text {rd }}$ ed., Microcosm Press, El Segundo, CA., and Kluwer Academic Publishers, Dordrecht, The Netherlands, 1999, pg. 702.

${ }^{22}$ Neptune Orbiter Mission Analysis Assumptions, In-Space Integrated Space Transportation Activity by the 2004 IISTP Systems Analysis Team, March 2004, (contact Larry Kos, MSFC, 256-544-1522)

${ }^{23}$ Noca, M. A., and Bailey, R. W., "Mission Trades for Aerocapture at Neptune," $40^{\text {th }}$ AIAA/ASME/SAE/ASEE Joint Propulsion Conference, AIAA 2004-3843, July 11-14, 2004.

${ }^{24}$ Oh, David Y., "Evaluation of Solar Electric Propulsion for Discovery Class Missions," $41^{\text {th }}$ AIAA/ASME/SAE/ASEE Joint Propulsion Conference, AIAA 2005-4270, July 11-14, 2005. 


\begin{tabular}{|c|c|c|}
\hline \multicolumn{2}{|c|}{ REPORT DOCUMENTATION PAGE } & $\begin{array}{l}\text { Form Approved } \\
\text { OMB No. 0704-0188 }\end{array}$ \\
\hline \multicolumn{3}{|c|}{$\begin{array}{l}\text { Public reporting burden for this collection of information is estimated to average } 1 \text { hour per response, including the time for reviewing instructions, searching existing data sources, } \\
\text { gathering and maintaining the data needed, and completing and reviewing the collection of information. Send comments regarding this burden estimate or any other aspect of this } \\
\text { collection of information, including suggestions for reducing this burden, to Washington Headquarters Services, Directorate for Information Operations and Reports, } 1215 \text { Jefferson } \\
\text { Davis Highway, Suite 1204, Arlington, VA 22202-4302, and to the Office of Management and Budget, Paperwork Reduction Project (0704-0188), Washington, DC 20503. }\end{array}$} \\
\hline 1. AGENCY USE ONLY (Leave blank) & \begin{tabular}{|c|c|} 
2. REPORT DATE & 3. \\
January 2006 &
\end{tabular} & $\begin{array}{l}\text { D DATES COVERED } \\
\text { echnical Memorandum }\end{array}$ \\
\hline \multicolumn{2}{|c|}{$\begin{array}{l}\text { Performance of Solar Electric Powered Deep Space Missions Using Hall } \\
\text { Thruster Propulsion }\end{array}$} & \multirow{2}{*}{ WBS-22-800-90-09 } \\
\hline \multicolumn{2}{|c|}{$\begin{array}{l}\text { 6. } \text { AUTHOR(S) } \\
\text { Kevin E. Witzberger and David Manzella }\end{array}$} & \\
\hline $\begin{array}{l}\text { 9. SPONSORING/MONITORING AGE } \\
\text { National Aeronautics and S } \\
\text { Washington, DC 20546-0C }\end{array}$ & $\begin{array}{l}\text { NAME(S) AND ADDRESS(ES) } \\
\text { Administration }\end{array}$ & $\begin{array}{l}\text { 10. SPONSORING/MONITORING } \\
\text { AGENCY REPORT NUMBER } \\
\text { NASA TM-2006-214044 } \\
\text { AIAA-2005-4268 }\end{array}$ \\
\hline
\end{tabular}

Prepared for the 41st Joint Propulsion Conference and Exhibit cosponsored by AIAA, ASME, SAE, and ASEE, Tucson, Arizona, July 10-13, 2005. Responsible person, Kevin E. Witzberger, organization code PBM, 216-433-3463.

12a. DISTRIBUTION/AVAILABILITY STATEMENT

12b. DISTRIBUTION CODE

Unclassified - Unlimited

Subject Categories: 12, 13, and 20

Available electronically at http://gltrs.grc.nasa.gov

This publication is available from the NASA Center for AeroSpace Information, 301-621-0390.

13. ABSTRACT (Maximum 200 words)

Power limited, low-thrust trajectories were assessed for missions to Jupiter, Saturn, and Neptune utilizing a single Venus Gravity Assist (VGA) and a primary propulsion system based on either a 3-kW high voltage Hall thruster, of the type being developed by the NASA In-Space Propulsion Technology Program, or an 8-kW variant of this thruster. These Hall thrusters operate with specific impulses below 3,000 seconds. A trade study was conducted to examine mission parameters that include: net delivered mass (NDM), beginning-of-life (BOL) solar array power, heliocentric transfer time, required launch vehicle, number of operating thrusters, and throttle profile. The top performing spacecraft configuration was defined to be the one that delivered the highest mass for a range of transfer times. In order to evaluate the potential future benefit of using next generation Hall thrusters as the primary propulsion system, comparisons were made with the advanced state-of-the-art (ASOA), 7-kW, 4,100 second NASA's Evolutionary Xenon Thruster (NEXT) for the same mission scenarios. For the BOL array powers considered in this study (less than $30 \mathrm{~kW}$ ), the results show that the performance of the Hall thrusters, relative to NEXT, is largely dependant on the performance capability of the launch vehicle, and that at least a 10 percent performance gain, equating to at least an additional $200 \mathrm{~kg}$ dry mass at each target planet, is achieved over the higher specific impulse NEXT when launched on an Atlas 551.

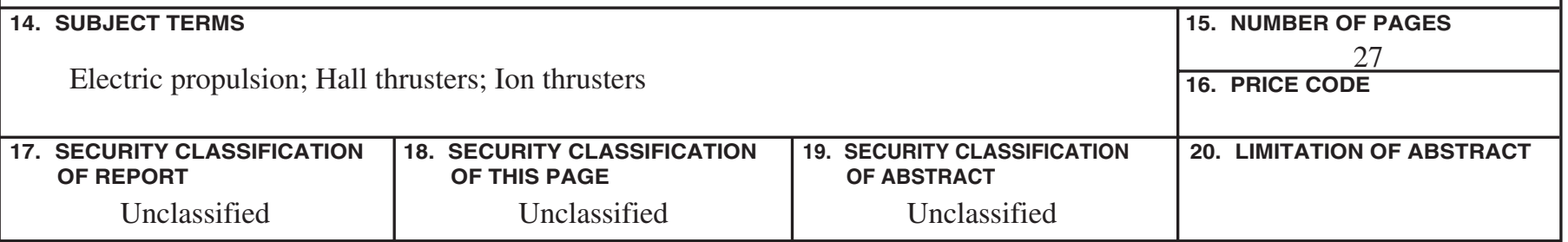



